\title{
Continuous Flash Suppression: Known and Unknowns
}

\author{
Ali Pournaghdali \& Bennett L. Schwartz* \\ Department of Psychology, Florida International University \\ Miami, Florida, 33199 \\ *Corresponding Author. Email: bennett.schwartz@,fiu.edu
}




\begin{abstract}
Studies utilizing continuous flash suppression (CFS) provide valuable information regarding conscious and nonconscious perception. There are, however, crucial unanswered questions regarding the mechanisms of suppression and the level of visual processing in the absence of consciousness with CFS. Research suggests that the answers to these questions depend on the experimental configuration and how we assess consciousness in these studies. The aim of this review is to evaluate the impact of different experimental configurations and the assessment of consciousness on the results of the previous CFS studies. We review studies that evaluated the influence of different experimental configuration on the depth of suppression with CFS and discuss how different assessments of consciousness may impact the results of CFS studies. Finally, we review behavioral and brain recording studies of CFS. In conclusion, previous studies provide evidence for survival of low-level visual information and complete impairment of high-level visual information under the influence of CFS. That is, studies suggest that nonconscious perception of lower-level visual information happens with CFS but there is no evidence for nonconscious highlevel recognition with CFS.
\end{abstract}

Keywords Visual consciousness; Nonconscious perception; Continuous flash suppression; Neural correlates of consciousness 


\section{Introduction}

The neural correlates of consciousness ${ }^{1}\left(\mathrm{NCCs}^{2}\right)$ and the differences between conscious and nonconscious perception are topics of interest in cognitive neuroscience. There are a variety of methods and techniques that are used to manipulate conscious and nonconscious perceptions, ranging from methods that target attentional processes, like inattentional blindness (Mack, 2003) and attentional blink (Martens \& Wyble, 2010), to the methods that manipulate conscious perception at the perceptual level, like visual masking (Bachmann \& Francis, 2013) and binocular rivalry (Tong, Meng, \& Blake, 2006). One of the newest methods, which has been used extensively in the recent years and is the focus of the current review, is continuous flash suppression (CFS; Tsuchiya \& Koch, 2005).

In CFS, the presentation of a series of masks $\left(\right.$ Mondrians $\left.^{3}\right)$ to the dominant eye suppresses the perception of low contrast target presented to the non-dominant eye. This can be achieved using three different display setups: red-blue or red-green anaglyph glasses, mirror stereoscopes and prism goggles (Carmel, Arcaro, Kastner, \& Hasson, 2010). CFS can be used to dissociate conscious perception from visual processes irrelevant to awareness. Because CFS has several advantages over other suppression methods, it has become a popular method in the field of visual awareness. These advantages include longer duration of invisibility than other similar methods such as binocular rivalry and flash suppression (Tsuchiya, Koch, Gilroy, \& Blake, 2006), and reliable suppression from the onset of target (e.g. Tsuchiya \& Koch, 2005). Despite these advantages of CFS for examining conscious and nonconscious perception, there are still many unanswered questions regarding this method, and the neural basis of suppression with CFS is still

\footnotetext{
${ }^{1}$ In this review, we use terms consciousness and awareness interchangeably.

${ }^{2}$ For a list of the abbreviations used in this study, see Appendix A.

${ }^{3}$ Because of the resemblance of these masks to the work of the artist, Piet Mondrian, they are named Mondrians. We, however, use the terms Mondrians, masks and maskers interchangeably to refer to this class of stimuli.
} 
unknown. Moreover, different researchers have used different experimental configurations to suppress the target stimulus and have used different strategies to evaluate conscious perception. One of our assertions is that the lack of homogeneous experimental configuration and behavioral assessments of conscious perception prevent us from generalizing the results of the studies that employ CFS. As we will show, this heterogeneity results in discrepancy of evidence regarding nonconscious perception of different visual categories and neural basis of nonconscious perception under the influence of CFS (it is important to note that this heterogeneity might be one of the reasons of the aforementioned discrepancies, and some other factors may also contribute to these discrepancies, which are beyond the scope of this review). Therefore, it is crucial to understand how different experimental configurations and behavioral assessments of consciousness influence the results of the CFS studies.

The current research program that utilizes CFS to understand the differences between conscious and nonconscious perception needs to provide answers to at least the following five questions, which are critical for the scientific understanding of conscious perception:

1- What is (are) the optimal experimental configuration(s) to obtain an optimal suppression?

2- What is (are) the optimal assessment(s) of consciousness?

3- What is the mechanism of suppression of CFS?

4- Can visual information be processed under the influence of CFS and in absence of awareness?

5- What is the level of visual processing under the influence of CFS?

To find an accurate response to the last three questions, we need to first find the optimal experimental configuration(s) and the optimal assessment(s) of conscious perception. Therefore, the first two questions are highly critical for the understanding of the mechanism of suppression 
and the level of nonconscious processing with CFS. Therefore, the aim of this review is to evaluate the impact of different experimental configurations and the assessment of consciousness on the results from previous CFS studies. To this end, we will first review different spatial and temporal properties of target and masks, which may impact the depth of suppression and processing of both masks and target under CFS. Second, we will review the methods to assess conscious perception and discuss a model-based analysis approach based on a multidimensional extension of signal detection theory, called general recognition theory (Ashby \& Soto, 2015; Soto, Zheng, Fonseca, $\&$ Ashby, 2017). Then, we will review some of the key findings regarding nonconscious perception with CFS. Finally, we will review some of the studies that explored the neural underpinnings of conscious and nonconscious perception using CFS.

Before moving to the next section, we clarify a specific point that is often questioned $^{4}$. Some may rightfully point out that "nonconscious perception" is not a proper term to use in order to refer to the visual processing in the absence of awareness and suggest using the term "nonconscious visual processing" instead. Although we acknowledge the implications of the differences in terminology, we argue that any visual processing in the absence of awareness that translates to behavioral responses (such as adaptation or priming. See section on Nonconscious perception with CFS) counts as a nonconscious perception. Based on this, if visual processing in the absence of awareness does not translate to a behavioral response, it does not qualify as nonconscious perception. Regardless of this argument, we will use two terms interchangeably, but we will not consider any visual/neural processing that does not translate to a behavioral response as an instance of nonconscious perception.

\footnotetext{
${ }^{4}$ We thank one of the anonymous reviewers for motivating us to clarify this point.
} 


\section{Influence of experimental configuration on CFS suppression}

Since Tsuchiya and Koch (2005) first introduced CFS, many studies used this method to evaluate nonconscious perception at the behavioral and neural level. Some of these studies, however, did not control or manipulate masks and targets' low-level attributes such as spatial and temporal frequencies. Subsequent studies, however, showed that strength of suppression is tightly correlated with spatial and temporal properties of target and masks in CFS. As we will see in the following sections, target and maskers' low-level attributes may explain some results with CFS (e.g. face and facial expression studies) and by controlling or manipulating specific attributes of maskers and targets, some of the nonconscious effects may disappear (for example in case of nonconscious recognition of manipulable objects. See section "Nonconscious perception of manipulable objects").

Therefore, it is possible that some CFS studies failed to induce complete suppression because of the inability of their experimental configurations to allow suppression of the targets. On the other hand, some settings might over-suppress the visual processing, meaning they might suppress both conscious and nonconscious processing. This may be one of the reasons of discrepancy in the CFS literature regarding different visual categories such as facial expression and tool recognition (see subsections "Nonconscious facial expression recognition" and "Nonconscious perception of manipulable objects"). Therefore, experimental configurations with optimal temporal and spatial parameters of targets and masks are essential parts of the CFS studies. Fortunately, in the past few years, a growing number of studies evaluated the role of these attributes in CFS related suppressions, and we review these studies in this section.

The first experimental parameter that needs to be set carefully is temporal frequency (TF) of the maskers (or masks). In their original study, Tsuchiya and Koch (2005) used masks with 10 
Hz TF to render the targets invisible. The majority of the CFS studies also followed Tsuchiya and Koch and used masks with $10 \mathrm{~Hz}$ TF (e.g. Almeida, Mahon, Nakayama, \& Caramazza, 2008; Anderson, Siegel, White, \& Barrett, 2012). Some studies, however, used TFs lower or higher than $10 \mathrm{~Hz}$, ranging from close to $0 \mathrm{~Hz}$ to $100 \mathrm{~Hz}$ (e.g. Geng, Zhang, Li, Tao, \& Xu, 2012). It seems that using different TFs for maskers, in some of the studies, is arbitrary and sometimes based on untested assumptions. For example, some studies used maskers with higher TF than $10 \mathrm{~Hz}$ based on the presumption that suppressive power of maskers increases with increase in maskers' TF (e.g. Geng et al., 2012; Xu, Zhang, \& Geng, 2011). Some studies do not report maskers' TF at all, and therefore these studies cannot be compared to other studies along any dimensions (e.g. Costello, Jiang, Baartman, McGlennen, \& He, 2009). Because TF varies or is not reported at all, generalization of the results across CFS studies is questionable at best (for a discussion regarding the generalizability of CFS studies, see Zhan, Engelen, \& de Gelder, 2018). Therefore, one of the goals of this paper is to stress to researchers the importance of adopting an optimal TF for their maskers to insure an optimal level of suppression.

In order to understand the influence of maskers' TF on target visibility we need to clarify the difference between maskers' TF with the modulation in temporal structure of the maskers' luminance. When masks replace each other with a specific TF, a broad energy spectrum in the temporal dimension is produced as the result of the changes in the luminance of the pixels within the maskers. This energy spectrum peaks at a much lower frequency (see Yang \& Blake, 2012). For example, presentation of maskers with $10 \mathrm{~Hz}$ TF produces a broad energy spectrum in the temporal dimension that peaks at $5 \mathrm{~Hz}$. This distinction leads to two different strategies to manipulate and evaluate the influence of maskers' TF on target visibility. In the first strategy, maskers' TF is evaluated by manipulating the duration of each mask (maskers' refresh rate). For 
example, for presenting 10 maskers with the frequency of $10 \mathrm{~Hz}$, each masker will be presented for $100 \mathrm{~ms}$ (for the total of 1 second), and for presenting 10 maskers with the frequency of $20 \mathrm{~Hz}$, each masker will be presented for 50 milliseconds (for the total of $500 \mathrm{~ms}$ ). For the remaining of this section, we refer to this strategy "refresh-based strategy."

The second strategy involves spectrum analysis of the maskers and filtering the energy spectrum in the temporal dimension. In this strategy, the changes in the luminance of the pixels within the presentation duration of the maskers are Fast Fourier transformed, and a band-pass filter (a filter that only allows frequency within a specific range to pass) is applied to the transformed signal in the temporal dimension (see Yang \& Blake, 2012). Finally, by Inverse Fourier Transformation of the signal, a modified set of maskers are produced from the old ones that have a specific temporal structure within a very specific range. For the remaining of this section, we refer to this strategy "spectral-based strategy."

In the past few years, some studies have utilized either of the abovementioned strategies to evaluate the influence of maskers' TF on the visibility of the target stimuli. Studies that adopted a spectral-based strategy showed that maskers with TFs lower than $10 \mathrm{~Hz}$ are more effective in suppressing the target stimulus than those maskers with TFs higher than $10 \mathrm{~Hz}$. In the first study, Yang and Blake (2012, Experiment 4) showed that Mondrians with low TF (below $10 \mathrm{~Hz}$ ) induce similar level of suppression as Mondrians with $10 \mathrm{~Hz}$ TF. Mondrians with high TF (above $10 \mathrm{~Hz}$ ) induced weaker suppression than Mondrians with $10 \mathrm{~Hz}$ TF. According to these results, high TF maskers are not as effective as maskers with $10 \mathrm{~Hz}$ and lower TFs to suppress the target stimuli. Further studies not only supported Yang and Blake's (2012) results, but showed that maskers with lower TF than $10 \mathrm{~Hz}$ might be more effective at suppression than $10 \mathrm{~Hz}$ TF maskers. For example, Han, Lunghi, and Alais (2016) showed that filtered noise-maskers (which were different from 
traditional Mondrians) with lower TF $(0.375,0.75,1.5$ and $3 \mathrm{~Hz})$, induced longer suppression duration than noise masker with zero $\mathrm{TF}$ (static masker) and noise-maskers with high $\mathrm{TF}(6.25$, 12.5 and $25 \mathrm{~Hz}$ ). High TF noise-maskers, however, induced shorted suppression duration than static masker. In addition, Han, Blake, and Alais (2018, Experiment 3), showed that Mondrians with lower TF (low-band pass Mondrians), have similar suppressive power (similar suppression duration) to Mondrians with $10 \mathrm{~Hz}$ TF (unfiltered Mondrians). In accordance with previous results, Han et al. (2018) showed that Mondrians with high TF (high-band pass Mondrians) have a lower suppressive power than low-band pass and unfiltered Mondrians.

Studies that adopted the refresh-based strategy supported the results of the spectral-based studies and showed that Mondrians with TF lower than $10 \mathrm{~Hz}$ have more suppressive powers than those with TF higher than $10 \mathrm{~Hz}$. For example, Zhu, Drewes, and Melcher (2016) showed that the targets, which were rendered invisible with 5 and $7 \mathrm{~Hz} \mathrm{TF}$ Mondrians, required higher contrast to break the suppression than targets that were rendered invisible with Mondrians with higher or lower TFs. Fitting skewed-normal curve to their data, Zhu et al. (2016) showed that the breakthrough contrast peaks at $6 \mathrm{~Hz}$ TF. Finally, Zhan, Engelen, et al. (2018), showed that Mondrians with lower TF than $10 \mathrm{~Hz}(4,6$ and $8 \mathrm{~Hz}$ ) induce more unseen trials (measured by yes/no detection task) than Mondrians with TF around $10 \mathrm{~Hz}$ and higher. In contrast with the preceding studies, Kaunitz, Fracasso, Skujevskis, and Melcher (2014) showed that Mondrians with TFs higher than $10 \mathrm{~Hz}(16.6$ and $28.5 \mathrm{~Hz})$ are more effective in suppressing a brief target, whereas Mondrians with TFs lower than $10 \mathrm{~Hz}(5$ and $8 \mathrm{~Hz})$ are not as effective as high TF Mondrians. This means that Mondrians with a high TF might be actually more effective than Mondrians with low TF.

In summary, studies point to three different Mondrians' TFs as optimal TF: TF close to zero (Han et al., 2016), TF between 5 to $7 \mathrm{~Hz}$ (with $6 \mathrm{~Hz}$ being most effective; Zhan, Engelen, et 
al., 2018; Zhu et al., 2016) and $28.5 \mathrm{~Hz}$ (Kaunitz et al., 2014). We think that there are two potential reasons for this discrepancy. First, Han et al. (2016) used noise-maskers that change smoothly, in contrast to traditional Mondrians that have sharp updates (that change abruptly). Second, studies that presented the target stimuli for a relatively long time, found TFs lower than $10 \mathrm{~Hz}$ as optimal TF (Han et al., 2018, 2016; Zhan, Engelen, et al., 2018; Zhu et al., 2016), whereas the study that presented the target relatively briefly, found TFs higher than $10 \mathrm{~Hz}$ as optimal TF $(28.5 \mathrm{~Hz}$; Kaunitz et al., 2014). Therefore, it seems the duration of target stimuli interacts with maskers' TF, and the maskers' optimal TF depends on the duration of the target.

Han and Alais (2018) provided supporting evidence for this conclusion. In their study, Han and Alais (2018) adopted the spectral-based strategy and showed that noise maskers with low TF are more efficient and powerful at inducing suppression when the target is presented for longer duration and is modulating with low frequency. Maskers with high TF are more efficient and powerful at inducing suppression when the target is presented briefly and is modulating with high frequency. Even though maskers with high TF are more effective at suppressing a brief target, it is also possible that this effectiveness is the results of distraction of attention by the maskers. That is, it could be possible that maskers with high TF do not induce enough suppression, but their rapid flickering distracts participants from attending the brief target. We think that this possibility should be investigated in the future studies.

In addition to the maskers' (and also targets') TF, spatial frequency (SF) of both targets and maskers is an essential attribute of a CFS experiment. Tsuchiya and Koch (2005, Experiment 5) and Yang and Blake (2012; Experiments 1 \& 2) showed that Mondrians with low SF are more efficient in suppressing targets than Mondrians with high SF. Moreover, Yang and Blake (2012) found strongest spectral power of the Mondrians in the low SFs, which might explain why 
Mondrians with low SF have more suppressive power than Mondrians with high SF. A follow up experiment showed that unfiltered and low band-pass filtered (low SF) Mondrians are more effective in suppressing the targets than high band-pass filtered (high SF) Mondrians (Yang \& Blake, 2012, Experiment 3). Moreover, the unfiltered and low SF Mondrians had stronger suppression effects on the targets with low SF than targets with high SF. These results indicate that low SF properties of Mondrians are essential parts of suppression with CFS, an important point which has both methodological and theoretical implications.

Han et al. (2016, Experiment 3), however, found that their noise-maskers yielded longer suppression durations for the natural image targets with high SF than those with low SF. It is not clear why there should be a difference between traditional Mondrians and the noise-maskers used by Han et al. (2016) in suppressing targets with low vs. high SF. In order to resolve this issue, we propose a study that compares the suppression impact of these two types on maskers on targets with different SFs, by equating the spectral power of the two types of maskers across different SFs.

Other visual attributes also impact the depth of suppression with CFS. For example, Han et al. (2018, Experiment 1) showed that the internal structure of the Mondrians is an important element of suppression, and disturbing the structural integrity of the Mondrians by phase scrambling reduces the suppressive power of them. In addition, Han et al. (2018, Experiment 2), showed that Mondrians with intact edges but phase-scrambled solid areas induce longer suppression duration than Mondrians with intact solid areas but phase-scrambled edges. Moreover, Mondrians with intact edges induce shorter suppression duration than intact Mondrians. Mondrians with intact solid area, however, did not induce longer suppression duration than phasescrambled Mondrians. Furthermore, reducing the structural integrity of the edges (60\% reduction) 
resulted in shorter suppression duration, regardless of structural integrity of the solid areas. Reducing the structural integrity of the solid areas (60\% reduction) only resulted in shorter suppression duration, when the structural integrity of the edges was intact or reduced slightly (20\% reduction). These results indicate that spatial edges are essential parts of integral structure of the Mondrians and therefore crucial elements of suppression. In line with this, Hong and Blake (2009) showed that removing the sharp edges of a bar stimulus, reduced the availability of participants to discriminate the orientation of the bar, meaning bars without sharp edges are more susceptible to CFS suppression. Therefore, maskers with intact spatial edges are more effective in inducing suppression than maskers without this property. This is important because some studies adopted maskers which lacked spatial edges and incomplete suppression might explain the results of these studies (e.g. Song \& Yao, 2016).

Another important visual attribute that may impact CFS-based suppression is color. Many studies have utilized chromatic Mondrians based on the presumption that colorful maskers induced stronger suppression than gray-scale maskers (e.g. Song \& Yao, 2016). Hong and Blake (2009), however, showed that chromatic and gray-scale Mondrians did not differ with respect to suppression of orientation of a bar stimulus. Using achromatic Mondrians to suppress a chromatic target stimulus, on the other hand, results in bleaching through of the color of the target. That is, bleaching means that when suppressing a chromatic target with achromatic Mondrians, participants reported experiencing the color of the target. In this situation, using chromatic Mondrians suppresses the color of the targets completely. In addition, Hong and Blake (2009) showed that chromatic Mondrians are less effective than achromatic Mondrians in suppressing moving targets. Therefore, it seems chromatic Mondrians are only useful when suppressing a chromatic target but not achromatic one. Based on this, some studies that used chromatic 
Mondrians to suppress an achromatic target may fail to induce suppression. Hence, it is important to interpret and generalize the results of such studies with more caution. Therefore, we recommend using achromatic Mondrians to suppress an achromatic target and using chromatic Mondrians to suppress a chromatic target.

Motion is another visual attribute that influences the depth of CFS related suppression. It seems traditional Mondrians are not as effective as moving Mondrians in suppressing a moving target (Moors, Wagemans, \& de-Wit, 2014). Having said that, there are two attributes of the moving Mondrians that need to be evaluated when evaluating the impact of moving Mondrians on a moving stimulus: speed and the pattern of motion. Moors et al. (2014) showed that moving Mondrians have more suppressive power when the speed of Mondrians and targets are alike (3\%s in experiment 1 and $2 / \mathrm{s}$ in experiment 2). When the target had speed of $5 \%$, however, moving Mondrians with the same speed did not cause stronger suppression than moving Mondrians with other speed rates. These results indicate that matching the speed of Mondrians and targets increases the depth of suppression. Ananyev, Penney, and Hsieh (2017), on the other hand, found that slow moving Mondrians ( $(1 \% \mathrm{~s}$ and $2 \% \mathrm{~s})$ are more effective than fast moving Mondrians $\left(3^{\circ}, 5\right.$ and $\left.8 / \mathrm{s}\right)$. Targets with high speed $(5 / \mathrm{s})$ broke the suppression faster and were detected more often than targets with low speed $(1 \%)$. When trajectory length of slow and fast target was controlled, Ananyev et al. (2017, Experiment 3) found that the fast target no longer broke the suppression faster than slow targets, but it was detected more often than slow targets. These results indicate that slow Mondrians are more effective than fast Mondrians, and fast targets are more immune to the impact of suppression than slow targets. Ananyev et al. (2017) also examined the impact of pattern of motion in moving Mondrians on the depth of suppression and found that matching the pattern of motion between target and moving Mondrians results in a weaker suppression. In 
contrast, linearly moving Mondrians result in longer suppression than Mondrians with rotational moving pattern. Therefore, moving Mondrians are more effective at inducing suppression than traditional Mondrians, but the evidence regarding the influence of the speed and the pattern of motion on the depth of suppression is not conclusive.

Finally, it has been shown that spatial density of Mondrians also impacts the depth of suppression in a CFS experiment in a way that reduction in spatial density of Mondrians weakens the depth of suppression (Drewes, Zhu, \& Melcher, 2018). Mondrians' spatial density interacts with their TFs such that when Mondrians' spatial density reduces, the optimal Mondrians' TF increases. Therefore, Mondrians with low spatial density have stronger suppression effect when they are presented with high TF. Mondrians with high spatial density, on the other hand, induce stronger suppression when they are presented with lower TF.

There are other important attributes that to the best of our knowledge, have not been studied yet, such as the difference between rectangular and circular Mondrians. Evaluating these attributes is important because there are some untested presumptions about the impact of these attributes. For example, circular Mondrians were used to suppress face stimuli based on the assumption that circular component of circular Mondrians has stronger suppressive power on face stimuli than rectangular Mondrians (e.g. Stein, Hebart, \& Sterzer, 2011, Experiment 4). Therefore, future studies should investigate the impact of these attributes on the depth of suppression.

In summary, different visual attributes may impact the depth of suppression with CFS. To utilize CFS, it is necessary to control or manipulate these attributes. That is, to obtain an optimal level of suppression with CFS, we must carefully adopt maskers with specific levels of each of the visual attributes we just reviewed. These visual attributes include temporal and spatial frequencies, color, as well as the internal structure and spatial density of the maskers. As we noted, the optimal 
level of each visual attribute of the maskers depends on the attributes of the targets. For example, when we wish to suppress a moving target, we should use moving Mondrians and when we wish to suppress a chromatic target, we should use chromatic Mondrians. Based on the studies that we reviewed in this section, we recommend the following points:

1- Temporal frequency (TF): To suppress a target with a long presentation duration, we recommend using Mondrians with low TF. To suppress a target with a short presentation duration, we recommend using Mondrians with high TF.

2- Spatial frequency (SF): any study that uses CFS to achieve suppression needs to perform a spectral power analysis and report the results (for an example, see Yang \& Blake, 2012). This helps us to generalize the results of CFS studies and facilitates replication of the previous studies. For example, if a researcher wishes to replicate a nonconscious effect with CFS, this researcher can adopt maskers with the same spectral power as the previous studies. Moreover, by comparing the spectral power of maskers across studies that evaluated nonconscious perception of a certain visual category (such as face recognition), researchers can draw a clearer conclusion regarding the opposing results.

3- Color: To suppress a chromatic target, we recommend using chromatic Mondrians. When the target stimulus is achromatic, we recommend using achromatic Mondrians. As we saw, chromatic Mondrians may even be less effective to suppress some types of target stimuli such as motion.

4- Motion: To suppress a moving target, we recommend using moving Mondrians. When adopting moving Mondrians, we must select moving Mondrians with specific speed and pattern of motion. Because the evidence regarding these two components are not conclusive and no other study has replicated the results of Ananyev et al. (2017) or Moors 
et al. (2014), we suggest that studies attempting to suppress a moving target evaluate the depth of suppression resulting from different speed and patterns of motion in a preliminary study.

5- Internal structure of the maskers: We recommend using Mondrians with intact solid areas and especially intact edges.

6- Spatial density: We recommend using Mondrians with high spatial density. Moreover, Mondrians' TFs should be adjusted based on the spatial density of them.

Hence, we suggest careful modification of the abovementioned attributes in any CFS study. Moreover, some researchers have matched the visual attributes of the maskers and the targets to obtain optimal suppression. That is, they have adopted similar visual attributes to optimally suppress the target stimulus. For example, Moors et al. (2014) found more effective suppression when matching the speed of Mondrians and the targets (but see Ananyev et al., 2017). This strategy is based on feature-selective suppression which is a well-known feature of binocular rivalry (see Alais \& Melcher, 2007). Based on this assumption, matching the visual attributes of the masks and the targets increases the depth of suppression (e.g. see Moors et al., 2014). For example, in some studies, circular Mondrians (those with elliptical ovals) were used to suppress a face stimulus based on the assumption that similarity between ellipses and faces will induce a stronger suppression (e.g. Izatt, Dubois, Faivre, \& Koch, 2014; Stein, Hebart, et al., 2011, Experiment 4; also see Yang, Brascamp, Kang, \& Blake, 2014).

There are, however, some evidence against this assumption. For example, Ananyev et al. (2017) showed that matching the pattern of motion between target and moving Mondrians results in a weaker suppression, and Yang and Blake (2012) showed that targets with high SF are less prone to the suppression with CFS, regardless of the maskers SF, and maskers with low SF are 
more effective in inducing suppression. Therefore, matching the SF of Mondrians and mask may not be a good strategy to obtain a strong suppression. Based on this, we believe that to utilize the feature-selective suppression for CFS-induced suppression, the future studies need to test this assumption carefully for different visual attributes.

\section{How to assess awareness in a CFS experiment?}

Regardless of the method used to study nonconscious perception, it is crucial to use an accurate and reliable measure of awareness to ensure that participants are not conscious of the target stimulus. If we cannot evaluate conscious perception with an acceptable accuracy, we are not able to make any conclusions regarding conscious and nonconscious perception. In this section, we will discuss some of the main methods for evaluating conscious perception and will discuss how to obtain a reliable assessment of consciousness. The focus will be on the differences between subjective and objective measures of conscious perception.

There are important differences between subjective and objective measures used to evaluate conscious perception (Persuh, 2018). When using subjective measures, researchers ask participants to report the visibility of the target (Dehaene \& Naccache, 2001; Lau, 2008). That is, participants are required to indicate if they consciously perceiving the target. We consider these measures as subjective because participants' reports in such tasks are based on their subjective experiences. Subjective measures' face validity is one of the main advantages of these measures, as they provide a direct assessment of subjective nature of conscious perception (Lau, 2008). There are a variety of subjective measures, which evaluate conscious perception directly or indirectly (by 
evaluating different cognitive phenomena related to consciousness). When using direct subjective measures, we can ask participants to use a yes/no detection task or a graded scale ${ }^{5}$.

In the yes/no detection task, participants are asked to judge the visibility of a target with two alternatives: yes (detecting or seeing the target) and no (not detecting or not seeing the target; see Dehaene \& Naccache, 2001) ${ }^{6}$. This task is popular because it is easy for participants to use, and it yields lower variance in threshold estimation than other methods (Lesmes et al., 2015). There are some issues with this method from both philosophical and experimental points of view, but the main problem is the problem of conservative criterion (Cowey, 2010; Goldiamond, 1958; also see Peters, Ro, \& Lau, 2016): When assessing participants' awareness using the yes/no detection task, they are more likely to use a conservative criterion to report the presence/absence of the target (see below). Moreover, this method has been criticized on the basis that it considers conscious perception as a dichotomous phenomenon, and therefore, it does not capture the subjective nature of conscious perception exhaustively and exclusively (Sandberg \& Overgaard, 2015; Timmermans \& Cleeremans, 2015). Because of this, some researchers used graded scales to evaluate conscious perception.

A graded scale, which has been utilized in a growing number of studies in the recent years, is the perceptual awareness scale (the PAS; Ramsøy \& Overgaard, 2004). When using the PAS, participants judge the visibility of the target stimulus by using four categories of perceptual responses: 'No experience', 'brief glimpse', 'almost clear experience and 'absolutely clear experience'. The PAS has advantages that make it an intuitive subjective measure of conscious

\footnotetext{
${ }^{5}$ The difference between these yes/no detection and graded measures is based on a controversy regarding the nature of subjective experiences: is conscious perception graded or dichotomous (this topic is beyond the scope of this review; we refer our readers to some of the many excellent reviews in this matter: Overgaard et al., 2006; Sergent \& Dehaene, 2004)?

${ }^{6}$ It is important to note that we use different terms to refer to detecting or not detecting the target, depending on the type of sensory system we are studying. For example, when one aims to study auditory consciousness (e.g. Dykstra, Cariani, \& Gutschalk, 2017), the two detection alternatives are hearing the target or not hearing the target.
} 
perception: it seems the PAS is an exhaustive measure of conscious perception, as it captures different levels of perception than complete visibility and invisibility (Sandberg, Bibby, \& Overgaard, 2013; Timmermans \& Cleeremans, 2015), and a participant's performance in the PAS correlates better with objective performance (Overgaard et al., 2006; Sandberg \& Overgaard, 2015; Sandberg, Timmermans, Overgaard, \& Cleeremans, 2010; see also Mazzi, Bagattini, \& Savazzi, 2016; Overgaard, Fehl, Mouridsen, Bergholt, \& Cleeremans, 2008). Furthermore, at least two studies found strong correlations between the PAS responses and the magnitude of neuronal signals recorded by EEG (Tagliabue, Mazzi, Bagattini, \& Savazzi, 2016) and MEG (Andersen, Pedersen, Sandberg, \& Overgaard, 2016).

There are some drawbacks related to the PAS. For example, the PAS effectiveness depends on the ability of participants to report their subjective experiences (Sandberg et al., 2010). Moreover, the borders between different levels of the PAS are not absolute and explicit, and this raises two issues: first, participants may get confused when using the PAS especially if they are not good introspectionists, and second, we can probably assume that there are more levels between the four proposed levels in the PAS (for a solution for these two issues; see Ramsøy \& Overgaard, 2004; Sandberg et al., 2013). Finally, using the PAS does not solve the problem of decision criterion. As with the yes/no detection task, participants may adopt a conservative (or even a liberal) criterion to categorize their subjective experiences with the PAS.

Some researchers prefer to use subjective, but indirect measures of conscious perception. These measures are called indirect because they assess conscious perception indirectly by evaluating related phenomena to conscious perception. One indirect measure is confidence ratings. In this task, participants rate their confidence concerning their performance or conscious perception (metacognitive confidence rating). This approach is based on the views that link 
conscious experiences with metacognition by stating that metacognitive experiences are essential parts of our phenomenology (Koriat, 2007; Kunimoto, Miller, \& Pashler, 2001; Metcalfe \& Schwartz, 2016; also see Lau \& Rosenthal, 2011; Rosenthal, 2019). Based on this approach, if a participant is highly confident, and if the confidence associates closely with accuracy, then he/she is consciously perceiving the target (e.g. Kunimoto et al., 2001; also see Peters \& Lau, 2015). In contrast, if a participant is not confident in his/her responses or the confidence does not associate with accuracy, he/she has no conscious perception of the target. Even though conscious perception and metacognitive experiences are tightly linked, there might be cases that these two are separated from each other (Charles, Van Opstal, Marti, \& Dehaene, 2013; Jachs, Blanco, Grantham-Hill, \& Soto, 2015; Reder, 1996). Consequently, metacognitive confidence ratings do not always represent conscious perception.

In general, confidence rating suffers from a similar issue as the PAS. As with the PAS, the different categories of confidence rating do not have clear and absolute borders. Subsequently, two participants with comparable conscious and metacognitive experiences may respond differently to confidence rating questions (Sandberg et al., 2010). Moreover, the problem of conservative criterion is a main issue when assessing conscious perception using confidence ratings. Therefore, like the PAS and yes/no detection task, participants may adopt a conservative criterion (see below for a potential solution for this issue).

We now switch to the objective measures of conscious perception. Using objective measures is another approach to evaluate conscious perception. In this approach, participants are asked to classify the category of the target or determine the interval in which the target was presented using a variety of objective tasks such as m-alternative forced choice (mAFC), minterval forced choice (mIFC), discrimination task, etc. Here the participant is not being asked if 
they perceived a target consciously or how confident they are that they saw a target, but where the target was or in what interval the target occurred. If an observer cannot perform this task at abovechance levels, we can assume that this participant is not aware of the target. These measures are called objective because it is believed that they provide an objective assessment of awareness (see Erikson, 1966). In this approach, a participant's performance is contrasted between a direct (objective) task and indirect task (e.g. priming and adaptation). We can observe a nonconscious perceptual effect, if participants are at chance-level in the direct task but above chance-level in the indirect task.

Some issues cast doubt on the adequacy of the objective measures for evaluating conscious vs. nonconscious perception. First, establishing that a participant's performance on an objective task is not different from chance-level requires proper statistical analysis such as power analysis (Sterzer, Stein, Ludwig, Rothkirch, \& Hesselmann, 2014; Yang et al., 2014). The majority of the studies, however, use traditional p-value testing methods, which may not be sufficient to establish the lack of awareness (accepting the null hypothesis; see Sterzer et al., 2014; Yang et al., 2014). Moreover, there are situations in which participants' performances are different from one objective task to another. For example, a participant's performance may be at chance-level in a 2AFC color discrimination task but above chance-level in a 2 AFC orientation discrimination task (Sterzer et al., 2014). Therefore, participant's conscious perception of the target depends on the type of the objective task that we use to evaluate it. That is, in the above example, we cannot assert that the participant is conscious or not. A potential solution for this problem is to use the same dimension (feature) in both direct and indirect tasks (Sterzer et al., 2014). For example, if researchers wish to study nonconscious perception of orientation, they should use the 2AFC orientation discrimination task as the measure of awareness. 
Two potential problems that we discussed already, lack of proper statistical analysis and the different levels of performance in the different objective tasks, are resolvable and relatively easy to avoid. There are, however, more fundamental problems that are often ignored. First, there is a common assumption that objective tasks such as mAFC and mIFC are bias free. But they are not, even though they are less susceptible to the adoption of a conservative criterion than subjective tasks (e.g. Cowey, 2010). More importantly, objective tasks are measures of performance, not conscious experience (Lau, 2008). When considering participants' performance in an objective task as a measure of awareness, we make an assumption that performance is the representation of conscious experience. But there are several situations in which there is a clear dissociation between conscious experience (measured by subjective tasks) and performance (measured by objective tasks). The classic example of this dissociation is blindsight. People with blindsight report that they are not able to perceive the target stimulus, which is presented inside the blind field. These people, however, have higher-than-chance performance in an objective task (Weiskrantz, 1986, 1996; Weiskrantz, Barbur, \& Sahraie, 1995). Therefore, if we assume that performance in an objective task represents conscious perception, then blindsight patients are not blind anymore and are able to perceive the targets consciously and have a normal visual life as people with normal and functional vision (see Rosenthal, 2019). Therefore, above-chance performance in an objective task does not necessary imply conscious perception, and in some cases, when using subjective tasks as the measure of conscious perception, above-chance performance in an objective task actually represents nonconscious perception.

Based on this, we argue that objective measures are not appropriate for evaluating conscious perception. Therefore, the contrast between direct (objective) and indirect (e.g. priming and adaptation) measures as the measure of nonconscious perception might not be an accurate 
measure of dissociation between conscious and nonconscious perception. This inadequacy might explain some of the null results from different blinding methods especially CFS. That is, in some of the previous studies, participants who had above-chance performance in an objective task were excluded from further analysis (e.g. Almeida, Mahon, \& Caramazza, 2010; Almeida et al., 2014; Barbot \& Kouider, 2012; Lapate et al., 2016). This means that the participants who were showing signs of nonconscious perception by having above-chance performance in an objective task, were excluded. Therefore, it is quite possible that some studies could not find evidence for nonconscious perception, only because they did not include participants who were showing signs of nonconscious perception.

Therefore, we think that subjective measures are better measures of awareness than objective measures. There are, however, some methodological concerns that may undermine the efficiency of the subjective measures that need to be addressed. When using subjective measures, above-chance discrimination performance (e.g. in the m-AFC, adaptation or priming task) in the trials that participants report they are not able to see the target (miss trials) is considered as the sign of nonconscious processing. The observed nonconscious effect resulted from this approach may be due to a statistical artifact, regression to mean (Shanks, 2017; for a comprehensive discussion on the problems of this approach, see Schmidt, 2015).

When evaluating nonconscious perception, the observed nonconscious perception might be the results of the difference between conscious and nonconscious processes or the result of adopting a conservative criterion in the detection task (this might be a decision bias or a perceptual bias; see Witt, Taylor, Sugovic, \& Wixted, 2015). Obviously, the former is the aim of studies that try to contrast these two modes of perception (e.g. see Peters \& Lau, 2015). The traditional methods, in which the performance accuracy is contrasted against chance-level in the miss trials 
(we call it "accuracy-based measures") are not able to separate the effects of perceptual and criterion processes. Therefore, a different method than accuracy-based measures is required to evaluate the contrast between conscious and nonconscious perception. One way to evaluate the aforementioned dissociation between conscious and nonconscious perception is by using signal detection theory (SDT; Green \& Swets, 1966; Macmillan \& Creelman, 2004). According to SDT, a perceptual effect is represented as a change in perceptual sensitivity ( $d^{\prime}$ or d-prime), which is the measure of ability of participants to discriminate signal from noise. SDT also provides a measure of bias, even though this measure represents both perceptual and decisional bias, and SDT is not able to measure these two types of bias separately (Witt et al., 2015). Based on this, $d^{\prime}$ can be the measure of interest in conscious research.

An important finding in the field of visual awareness is related to the higher sensitivity of blindsight patient GY in a 2AFC task than the yes/no detection task (Azzopardi \& Cowey, 1997), meaning GY's ability to discriminate signal from noise in the conscious detection task is abolished completely (yes/no detection $\mathrm{d}^{\prime}=0$ ), but he is able to discriminate signal from noise in an objective 2AFC task (discrimination d' higher than 0; also see Azzopardi \& Cowey, 1998). This means that we can consider higher $\mathrm{d}^{\prime}$ value in an objective task as compared to a subjective task as the psychophysical signature of perception in the absence of awareness ${ }^{7}$ (Balsdon \& Azzopardi, 2015; Heeks \& Azzopardi, 2015; Lloyd, Abrahamyan, \& Harris, 2013; Yoshida \& Isa, 2015; but see Peters et al., 2016), which could be a more accurate assessment of conscious and nonconscious perception than accuracy-based measures. We can use this approach when using confidence ratings as the measure of awareness. In this situation, nonconscious perception is represented by higher

\footnotetext{
${ }^{7}$ It is important to note that SDT assumes a mathematical relationship between d's of detection and 2AFC (or 2IFC) tasks: d'(detection) = $\mathrm{d}^{\prime}(2 \mathrm{AFC}) * \sqrt{2}$
} 
sensitivity in the objective task than in confidence rating sensitivity (note that metacognitive confidence rating sensitivity is different from sensitivity in the detection or objective task. We will discuss metacognitive sensitivity below). Although this new approach (which we call it "SDTbased analysis") is an improvement over the approach that utilizes the accuracy-based measures, to our surprise, only a few studies have adopted this approach (e.g. Balsdon \& Azzopardi, 2015; Heeks \& Azzopardi, 2015; Lloyd et al., 2013; Yoshida \& Isa, 2015), and to the best of our knowledge, no CFS study has done so.

There are, however, at least two limitations regarding the SDT-bases approach that need to be addressed. First, although we can use this approach to investigate the dissociation between conscious and nonconscious processing, it may not be suitable to answer some of the most important questions in the field of consciousness research (e.g. can perceptual processing happen in the absence of awareness?). Second, we can use this approach only if the subjective and objective tasks measure two different formats of the same underlying construct (e.g. yes/no detection and 2IFC detection tasks as the measures of conscious and nonconscious perception, respectively; see Azzopardi \& Cowey, 1997; Heeks \& Azzopardi, 2015). Therefore, one cannot compare sensitivity of two different tasks that measure two different constructs (e.g. yes/no detection and 2-choice discrimination of orientation tasks). Therefore, a new analysis approach is needed to evaluate conscious and nonconscious perception. We argue that the model-based analysis that we will describe in the next few paragraphs will solve these issues and assess conscious and nonconscious perception more rigorously.

Recently, Pournaghdali and colleagues introduced a novel model-based analysis approach based on a multidimensional extension of SDT, called general recognition theory (GRT; Ashby \& Soto, 2015; Soto et al., 2017) to evaluate perceptual processing in the absence of awareness 
(Pournaghdali, Schwartz, Hays, \& Soto, under revision). By fitting GRT model to a data collected from yes/no detection and 2-choice discrimination task, Pournaghdali and colleagues constructed a curve called the sensitivity vs. awareness (SvA) curve. The SvA curve depicts conditional sensitivity of participants in a discrimination task (e.g. 2AFC, priming and adaptation task) for each level of relative likelihood of awareness (see Figure 1; also see Pournaghdali et al., under revision, Figure 1b). By providing an objective benchmark (criterion) based on an ideal observer, the SvA curve divides the distribution of relative likelihood of awareness in two areas: the area (or region) of high likelihood of awareness and the area (or region) of low likelihood of awareness (it is important to note that $\mathrm{x}$ axis in the SvA curve is labeled "relative likelihood of no awareness." Based on this, in the $\mathrm{x}$ axis of an SvA curve, zero represents high level of awareness, and higher values in this axis represents higher likelihood of not being aware. See figure 1).

By evaluating the pattern resulted from the SvA curve, we can determine whether perceptual processing necessary for a perceptual discrimination task is awareness-dependent (Figure 1). That is, we can specify if a specific visual processing is dependent or independent of awareness. Independence between a specific visual processing and awareness is represented in the SvA curve as a consistent level of conditional sensitivity of the discrimination performance (henceforth sensitivity) at all levels of the relative likelihood of awareness (Figure 1A). The dependency of visual processing on awareness is represented by systematic change in the sensitivity as the function of the relative likelihood of awareness. If sensitivity drops as the likelihood of awareness drops and reaches zero before reaching the region of low likelihood of awareness (before objective criterion), then this visual processing requires awareness, and nonconscious perception of this class of visual stimulus does not occur (Figure 1B). In two situations, however, dependency of visual processing on awareness implies nonconscious 
perception. First, if sensitivity drops as the likelihood of awareness drops but does not reach zero before objective criterion, then we will have a visual processing that could happen in the absence of awareness (Figure 1C). In this case, the nonconscious processing is weaker than conscious processing but is still reliable. Finally, it is possible that the sensitivity is above zero only in the area of low likelihood of awareness and it rises as the likelihood of awareness drops (Figure 1D). This is a case of nonconscious perception in which the processing of information might actually improve in the absence of awareness (see also Newell \& Shanks, 2014).

The SvA curve has some unique features that make it an appealing approach to evaluate conscious and nonconscious perception: First, the SvA curve considers awareness as a non-binary continuous phenomenon. That is, even when the yes/no detection task is used to assess awareness, the SvA curve converts the responses into a continuous distribution. This potentially solves a problem that faces the yes/no detection task. That is, even if participants report their experiences with a dichotomous task, the SvA curve helps to capture the graded nature of awareness. Second, the SvA curve is compatible with different measures of awareness such as the PAS or metacognitive confidence ratings (see Pournaghdali et al., under revision, Supplementary Material). More importantly, by utilizing the objective benchmark that is different from subjective criterion, the SvA curve provides a bias-free assessment of conscious and nonconscious perception. Finally, the SvA also depicts the subjective criteria of all the participants. This in turn will help researchers to evaluate participants' response bias with more accuracy. Thus, we think that this model-based analysis captures the same psychophysical effects as the previous SDT-based approach (e.g. Azzopardi \& Cowey, 1997; Heeks \& Azzopardi, 2015), but with a greater resolution. Hence, this approach allows us to obtain a finer understanding of the dissociation 
between conscious and nonconscious perception, and the level of processing in the absence of awareness across different perceptual paradigms and tasks (Pournaghdali et al., under revision).

One final note is that we can evaluate sensitivity while using metacognitive confidence ratings as the measure of conscious perception. For this purpose, a different measure of sensitivity has been proposed: metacognitive (or type 2) sensitivity (type 2 d'; for review, see Fleming \& Lau, 2014). There are, however, different versions of type $2 \mathrm{~d}^{\prime}$. In one version, Kunimoto et al. (2001) proposed a sensitivity measure called a', which follows similar assumptions as traditional $\mathrm{d}^{\prime}$ (type $1 \mathrm{~d}^{\prime}$ ). This measure, however, is not bias free (Evans \& Azzopardi, 2007) and does not measure metacognitive sensitivity accurately.

Recently, another measure of metacognitive sensitivity was proposed which does not hold the same assumptions as type $1 \mathrm{~d}^{\prime}$ and is a more accurate measure of metacognition as it can differentiate type 2 sensitivity with more precision than other measures: meta-d' (Maniscalco \& Lau, 2012, 2014; also see Fleming \& Lau, 2014). Therefore, if researchers wish to use metacognitive confidence rating as the measure of conscious perception, it is advisable to use meta-d'. We emphasize this issue because recently a few studies evaluated conscious perception using metacognitive ratings and used $\mathrm{a}^{\prime}$. 


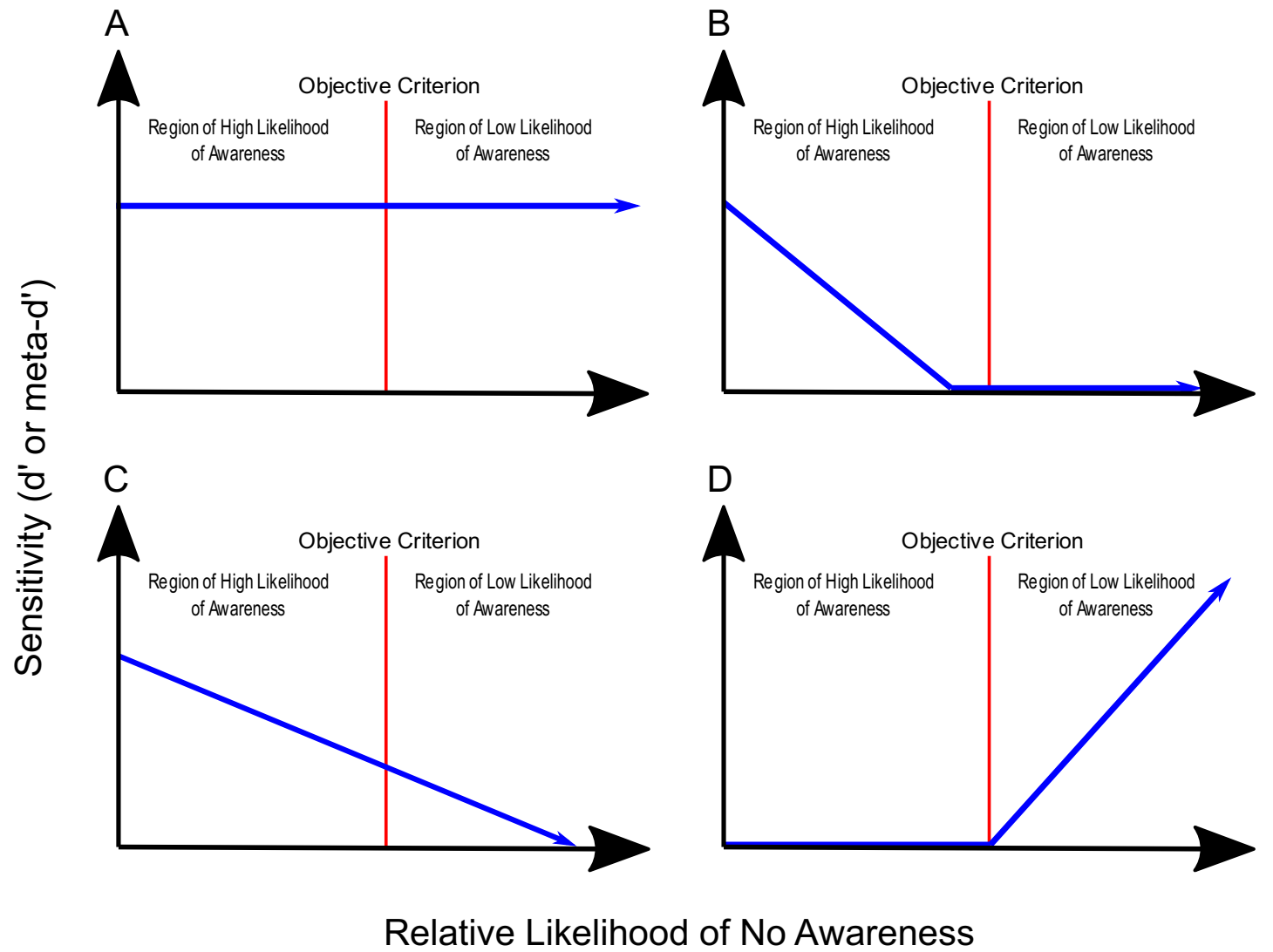

Fig. 1 Sensitivity vs. Awareness Curve. This graph depicts four different SvA curves. In each graph, the x axis represents "the relative likelihood of no awareness" with zero means that participant is consciously perceiving the target. As we move toward the higher values in the $\mathrm{x}$ axis, participants likelihood of not being aware of the target (relative likelihood of no awareness) increases. The y axis represents participants sensitivity in the perceptual task (e.g. priming, visual aftereffect, discrimination task). Zero sensitivity represents chance level. The red vertical line represents the objective criterion based on the optimal observer (see (Pournaghdali et al., under revision). This line divides the SvA graph into two areas: the region of high likelihood of awareness (left) and the region of low likelihood of awareness (right). The four graphs depict different possibilities of the association between consciousness and perceptual processing. The top left graph (A) represent a condition in which there is no association between awareness and a specific perceptual processing. The top right graph (B) represents a condition in which a specific perceptual processing depends on awareness. In this condition, as the likelihood of awareness drops, so does the sensitivity. However, the sensitivity in this condition reaches zero before the objective criterion and in the area of high likelihood of awareness. This means this specific type of perceptual processes depends on consciousness and it does not exist in the absence of awareness. The bottom left graph (C) represent a situation in which sensitivity drops as the likelihood of awareness drops and reaches zero after the objective criterion and in the area of low likelihood of awareness. The higher-than chance sensitivity (sensitivity higher than zero) in the area of low likelihood of awareness indicates nonconscious perception. Finally, the bottom right graph represents a situation in which the sensitivity is at the chance level in the area of high likelihood of awareness, but it starts improving after the objective criterion and in the area of low likelihood of awareness. Note that we can use different measures of awareness to evaluate awareness with SvA curve. Moreover, the y axis can also represent type $2 \mathrm{~d}^{\prime}$-or meta-d'. For this, SvA curve represents changes in the ability of metacognitive system to evaluate perceptual processing as the function of awareness.

We can model meta-d' using the SvA curve as well. In this situation the SvA curve represents meta-d' as the function of likelihood of awareness. That is, instead of measuring type 1 
sensitivity, the SvA curve can assess meta-d'. We can use this SvA curve to address some of the main questions regarding consciousness and metacognition: What is the nature of the association between consciousness and metacognition? Is consciousness dependent on metacognition? And can we observe metacognitive processes in the absence of awareness (See Pournaghdali et al., under revision)?

In conclusion, the assessment of consciousness is a critical part of any study in the field of consciousness, and we need to evaluate consciousness with the best tools available and analyze the results with proper statistical techniques. In the next two sections we focus on the behavioral and neural evidence regarding nonconscious recognition of different visual categories with CFS, in light of the sections that we just discussed. That is, we try to draw a clearer picture regarding the nonconscious perception with CFS and see if experimental configuration and assessment of awareness has any impact on the results of previous studies.

\section{Nonconscious perception with CFS}

When presenting participants with a target stimulus within the CFS paradigm, participants report that they are not able to see the target consciously. However, participants show signs of nonconscious vision via a variety of methods, including adaptation aftereffects, priming effects, breaking time of the suppressed target, and above-chance performance in an objective discrimination task. One way to evaluate nonconscious perception is by examining participants' performance in an objective discrimination task against chance-level in the trials that participants report not seeing the target. Above-chance performance in these trials indicates nonconscious perception of the invisible target. 
In an adaptation aftereffect study, prolonged exposure to a stimulus (the adaptor), with a specific property (such as left to right motion) causes participants to perceive the subsequent target (which is neutral in regard to the dimension of the interest), as having a property opposite to the adaptor (right to left motion). For example, if the adaptor is a male face and the target is a face that can be seen as male or female, participants report the target face as a female face (gender aftereffect; e.g. Afraz \& Cavanagh, 2009; Ng, Boynton, \& Fine, 2008). In contrast, in a priming study, presentation of a prime facilitates perception of the subsequent target, if the target is congruent with the prime. This priming effect shows itself through faster reaction time and more accurate classification of the target (e.g. Bar \& Biederman, 1998). Both adaptation aftereffect and priming effect could occur if the adaptor or the prime is visible (conscious or visible condition) or invisible (nonconscious or invisible condition). Moreover, if the effect transfers between the two eyes and if the effect is observed despite different target's and prime's (or adaptor's) size, we can assume that the effect is not low-level. Otherwise, the effect is high or at least mid-level.

Another way of evaluating nonconscious perception with CFS is to use a variant of CFS called "breaking continuous flash suppression" or bCFS (Jiang, Costello, \& He, 2007). In the bCFS paradigm, an experimenter measures the time that a target stimulus needs to break the suppression of the masks (detection time), such that the participant becomes aware of the target. In this type of study, researchers usually consider the systematic difference between the breaking times of two targets as the nonconscious advantage of a target that overcome the suppression faster. For example, if upright faces break the suppression faster than inverted faces, it indicates that face stimuli are being processed nonconsciously under the influence of CFS (for a critical review on bCFS, see Gayet, Van der Stigchel, \& Paffen, 2014). 
A main question here is the extent to which the visual information is processed under the influence of CFS. That is, researchers try to investigate the possibility of processing of high-level visual information (e.g. face identity, facial expression, semantic information, etc.) during CFS. There are, however, criteria for establishing high-level visual perception in the absence of awareness. If any of these criteria do not hold for any high-level visual category, we question the high-level nonconscious perception of that category. First, any study investigating high-level nonconscious perception should rule out any involvement of low-level features (e.g. contours, contrast, shapes) on the observed nonconscious effect (Moors et al., 2019; Moors, Hesselmann, Wagemans, \& van Ee, 2017). Second, a high-level nonconscious perception should be replicated at least once, as a matter of good methodological procedure (Moors et al., 2019). If a high-level nonconscious perception is only observed in one study, we should be careful in interpreting the results of that study.

Finally, positive results from bCFS studies are not sufficient to conclude that there is highlevel nonconscious perception. That is, in addition to bCFS results, other studies should provide support for high-level visual processing in the absence of awareness (Moors et al., 2019). This is important because in order to establish a nonconscious effect with bCFS, one needs to compare the detection time resulted from bCFS with the detection time resulted from a binocular control condition that mimics the bCFS (see Jiang et al., 2007). Researchers usually consider presence of the effect (difference between the detection times of the two or more target stimuli) in the bCFS condition and a null or a weaker effect in the control condition as the sign of nonconscious perception. This approach, however, does not provide a conclusive evidence for pure nonconscious processing under the influence of CFS because the differences between bCFS and control condition may arise not only from the nonconscious processes, but also from other factors that are 
not related to the nonconscious processing (Stein, Hebart, et al., 2011; also see Gayet et al., 2014). Therefore, establishing a pure nonconscious perception with bCFS is difficult, and we should always interpret bCFS results with caution.

Therefore, based on these criteria and based on our discussion on the experimental configuration and the assessment of consciousness, we review some of the important findings regarding the nonconscious perception of different classes of target stimuli with CFS. For each visual category, we present a table summarizing the experimental configuration and the assessment of awareness, used in each study (Tables 1 through 7). In the current section, we focus on the level of visual processing in the absence of awareness with CFS as well. Our intention is to explore what the evidence tell us about the nature of nonconscious perception when employing CFS. We also refer our readers to other reviews on CFS that we think they are relevant (Faivre, Berthet, \& Kouider, 2014; Moors, 2019; Yang et al., 2014).

\section{Nonconscious perception of orientation}

Early CFS studies (Bahrami, Carmel, Walsh, Rees, \& Lavie, 2008; Kanai, Tsuchiya, \& Verstraten, 2006) provided evidence for nonconscious adaptation of orientation with CFS. However, Peremen and Lamy (2014) did not find a reliable nonconscious priming effect (faster and more accurate response to the presentation of the congruent target to the prime) when the target was invisible with CFS. According to Koivisto and Grassini (2018), however, several methodological issues such as long presentation duration of the prime, similarity of some parts of the mask with the target and the prime contrast, may explain the null result of Peremen and Lamy (2014). Therefore, Koivisto and Grassini (2018) evaluated the nonconscious influence of an invisible prime (right/left oriented arrow), presented for a shorter duration than Peremen and Lamy's (2014) study, on the processing of the target and found that the congruent target/prime pair elicits a faster and more 
accurate response than the incongruent pair, meaning CFS does not interrupt nonconscious processing of the prime. In contrast to Peremen and Lamy (2014), Koivisto and Grassini (2018) found evidence for nonconscious priming of orientation with CFS. Therefore, Koivisto and Grassini's (2018) study and adaptation aftereffect studies of orientation provided an irrefutable support for nonconscious perception of orientation with CFS.

In addition, Song and Yao (2016) showed that participants classify the orientation of an invisible Gabor patch at above chance-level in a nonconscious 2AFC task. Song and Yao (2016) also showed overall improvement in nonconscious visual perception of three visual categories (right/left orientation, face/house and happy/sad face) with increasing the target luminance, but it is not clear if the nonconscious perception of orientation changed with change in luminance because they did not present the luminance results for separate categories (Song \& Yao, 2016, figure 3). Hong (2015) provided evidence for preferential processing of radial orientation ${ }^{8}$, while suppressing the visual stimulus using CFS. In this study, Hong (2015, Experiment 1) showed that sinusoidal Gabor patch stimuli with radial orientation break the suppression faster than those stimuli with tangential orientation. This means that participants not only are able to processes orientation nonconsciously, but also have preferential processing for specific orientations.

To summarize, despite the differences in experimental configuration and assessments of awareness between studies discussed in this section, a majority of them showed that even though CFS disrupts conscious perception of target, orientation is being processed in a nonconscious manner. That is, these studies provided conclusive evidence for nonconscious perception of orientation under the influence of CFS. Therefore, we can conclude that orientation is being

\footnotetext{
${ }^{8}$ Radial orientation refers to a situation in which the orientation and the location of the target are homogenous. For example, if a Gabor patch is left tilted and the target is in the top left or bottom right side of the screen, the Gabor patch has a radial orientation. Otherwise the orientation is tangential.
} 
processed under the influence of CFS (see Table 1 for a summary of the experimental configuration and the assessment of awareness in the studies that evaluated nonconscious perception of orientation with CFS).

Table 1 Experimental configuration and the awareness task in the studies that evaluated nonconscious perception of orientation.

\begin{tabular}{|c|c|c|c|c|c|c|c|}
\hline Study & Masks' Type & Masks' TF & Masks' SF & Colorful Masks? & Colorful Target? & Awareness task & $\begin{array}{l}\text { Is awareness } \\
\text { assessed in the } \\
\text { main block? }\end{array}$ \\
\hline $\begin{array}{l}\text { Bahrami et al. } \\
(2008)\end{array}$ & Mondrians & $30 \mathrm{~Hz}$ & NR* & Yes & No & Objective + CR & No \\
\hline $\begin{array}{l}\text { Kanai et al. } \\
(2006)\end{array}$ & Mondrians & $15 \mathrm{~Hz}$ & NR & Yes & No & Yes/No & No \\
\hline $\begin{array}{l}\text { Peremen \& } \\
\text { Lamy (2014) }\end{array}$ & Mondrians & $10 \mathrm{~Hz}$ & NR & Yes & No & The PAS & Yes \\
\hline $\begin{array}{l}\text { Koivisto \& } \\
\text { Grassini (2018) }\end{array}$ & Mondrians & $11 \mathrm{~Hz}$ & NR & Yes & No & $\begin{array}{l}\text { Objective }+ \text { The } \\
\text { PAS }\end{array}$ & Yes \\
\hline $\begin{array}{l}\text { Song \& Yao } \\
(2016)\end{array}$ & Mondrians & $33.33 \mathrm{~Hz}$ & NR & Yes & No & $\begin{array}{l}\text { Subjective } \\
\text { Graded Scale }\end{array}$ & Yes \\
\hline (Hong, 2015) & Mondrians & NR & NR & No & No & NA** & NA \\
\hline
\end{tabular}

*NR: Not Reported. **For the bCFS studies, we did not report the awareness measures in this and the following tables, because the awareness measure in bCFS studies have a different application than other type of nonconscious studies.

\section{Nonconscious face recognition}

Early adaptation studies with CFS showed that awareness is necessary for processing of face stimuli, and an invisible adaptor fails to induce the nonconscious face aftereffect with CFS (Amihai, Deouell, \& Bentin, 2011; Moradi, Koch, \& Shimojo, 2005). In addition, Shin, Stolte, and Chong (2009) showed that an invisible face induces gender aftereffect only if participants direct their attention to the location of the adaptor. The nonconscious aftereffect, however, disappears when participants direct their attention to a location other than the adaptor's. Moreover, Stein and Sterzer (2011) showed that an invisible adaptor induces face shape adaptation only when the adaptor and the target are presented to same eye and have the same size. According to Stein and Sterzer (2011) if we present the target and the adaptor to different eyes or when they are presented to the same eye but with different sizes, the adaptation aftereffect disappears, indicating this aftereffect is rather low-level. Finally, Stein, Peelen, and Sterzer (2012) provided evidence for 
nonconscious eye gaze adaptation with CFS, when both the target and the adaptor were presented to the same or different eyes. This adaptation, however, disappeared when the target and the adaptor were presented with different size. Overall, preceding studies indicate that the nonconscious high-level adaptation of face stimuli is impaired under the influence of CFS, as compared to face adaptation when the adaptor is consciously visible.

Nonconscious face priming studies provide further evidence for the idea that CFS impairs high-level face recognition and indicate that nonconscious face recognition with CFS might be due to the process of lower-level features of the face stimuli. Barbot and Kouider (2012), for example, showed that when an invisible face prime is presented for $60 \mathrm{~ms}$, it facilitates perception of a subsequent face target (only when is presented to the same eye as the prime). The invisible prime has an inhibitory influence on the processing of the target, when it is presented for $1000 \mathrm{~ms}$. According to Barbot and Kouider (2012), we observe the facilitatory and inhibitory impacts of short and long invisible prime, only when both the prime and the target are presented to the same eye. This means that the nonconscious face priming with CFS is rather low-level. Moreover, Izatt et al. (2014) found that face identity priming (when prime and target have different view point) and face repetition priming (when prime and target have same view point) are abolished when rendering the prime invisible for $50 \mathrm{~ms}$ with CFS and concluded that CFS interferes with face perception at a lower level of visual processing. Moreover, Izatt et al. (2014) showed that face priming impairment is associated with chance-level performance in a 2AFC task. Gelbard-Sagiv, Faivre, Mudrik, and Koch (2016) also showed that we can observe nonconscious face priming with CFS, but only when participants report that they are aware of lower level visual features of the prime like color (Experiment 1) and location (Experiment 2). According to Gelbard-Sagiv et al. (2016), in absence of low-level awareness, the invisible prime is unable to induce nonconscious 
impact on the target. Therefore, results from priming studies also indicate that CFS impairs nonconscious high-level face recognition, and any observed nonconscious face priming is rather the result of low-level features of the prime and the target (see Table 2 for a summary of the experimental configuration and the assessment of awareness in the priming and adaptation aftereffect studies of face recognition with CFS).

Table 2 Experimental configuration and the awareness task in the priming and aftereffect studies of nonconscious face recognition.

\begin{tabular}{|c|c|c|c|c|c|c|c|}
\hline Study & Masks' Type & Masks' TF & Masks' SF & Colorful Masks? & Colorful Target? & Awareness task & $\begin{array}{l}\text { Is awareness } \\
\text { assessed in the } \\
\text { main block? }\end{array}$ \\
\hline $\begin{array}{l}\text { Amihai et al. } \\
\text { (2011) }\end{array}$ & Mondrians & $10 \mathrm{~Hz}$ & NR & Yes & No & $\begin{array}{l}\text { Yes/No (report a } \\
\text { breakthrough)** }\end{array}$ & Yes \\
\hline $\begin{array}{l}\text { Moradi et al. } \\
\text { (2005) }\end{array}$ & $\begin{array}{l}\text { Moving } \\
\text { Random Dot }\end{array}$ & NR* & NR & No & No & $\begin{array}{l}\text { Yes/No (report a } \\
\text { breakthrough) }\end{array}$ & Yes \\
\hline $\begin{array}{l}\text { Shin et al. } \\
\text { (2009) }\end{array}$ & $\begin{array}{l}\text { Dynamic Radial } \\
\text { Gratings }\end{array}$ & $1 \mathrm{~Hz}$ & NR & No & No & $\begin{array}{l}\text { Yes/No (report a } \\
\text { breakthrough) }\end{array}$ & Yes \\
\hline $\begin{array}{l}\text { Stein et al. } \\
(2012)\end{array}$ & Mondrians & $10 \mathrm{~Hz}$ & NR & Yes & No & $\begin{array}{l}\text { Yes/No (report a } \\
\text { breakthrough) }\end{array}$ & Yes \\
\hline $\begin{array}{l}\text { Barbot \& } \\
\text { Kouider (2012) }\end{array}$ & Mondrians & $8 \mathrm{~Hz}$ & NR & Yes & No & Objective & No \\
\hline $\begin{array}{l}\text { Izatt et al. } \\
(2014)\end{array}$ & Mondrians & $10 \mathrm{~Hz}$ & NR & No & No & $\begin{array}{l}\text { Objective }+ \text { The } \\
\text { PAS }\end{array}$ & Yes \\
\hline $\begin{array}{l}\text { Gelbard-Sagiv } \\
\text { et al. (2016) }\end{array}$ & Mondrians & $10 \mathrm{~Hz}$ & NR & No & Yes & $\begin{array}{l}\text { Objective + The } \\
\text { PAS }\end{array}$ & Yes \\
\hline
\end{tabular}

*In this study, authors did not report the speed of the moving dots. ${ }^{* *}$ In such studies, the researchers asked participants to report seeing anything other than the mask during or after the trial. Therefore, they did not use the traditional Yes/No detection task.

Whereas results from adaptation and priming studies indicate that face recognition is impaired by CFS, several bCFS studies provide evidence for nonconscious face recognition under the influence of CFS. Using the bCFS technique, different studies have shown that upright faces break the suppression faster than inverted faces (Jiang et al., 2007; Stein, Peelen, \& Sterzer, 2011; Stein, Reeder, \& Peelen, 2016; Zhou, Zhang, Liu, Yang, \& Qu, 2010), indicating that the highlevel processing of face stimuli may survive under the influence of CFS. Furthermore, other bCFS studies showed that participants' own face (Geng et al., 2012, Experiment 1), faces with direct gaze (Chen \& Yeh, 2012; Stein, Senju, Peelen, \& Sterzer, 2011; Yokoyama, Noguchi, \& Kita, 
2013, Experiment 1), faces belong to familiar identities (Gobbini, Gors, Halchenko, Rogers, et al., 2013), faces oriented toward the observer (Gobbini, Gors, Halchenko, Hughes, \& Cipolli, 2013) and faces, which are experienced in a congruent configuration (Moors, Wagemans, \& de-Wit, 2016) overcome the suppression faster. In addition, Hung, Nieh, and Hsieh (2016) showed that in comparison to invisible unattractive faces, invisible attractive faces break the suppression faster (Experiment 1), have lower detection threshold (Experiment 2), and nonconsciously direct spatial attention (Experiment 3; also see Nakamura \& Kawabata, 2018). Therefore, results from bCFS studies may indicate the survival of face recognition processes in the absence of awareness while employing CFS. But as we discussed at the beginning of this section, the observed nonconscious effects from bCFS studies may not be the result of pure nonconscious processes, and other factors may influence these effects. Based on this, the results from bCFS studies should be interpreted with caution.

To summarize, adaptation and priming studies showed that CFS impairs high-level face recognition, even though results from bCFS studies provided supports for the survival of highlevel face recognition under the influence of CFS. Because bCFS studies are the only ones that provided support for the nonconscious high-level face recognition with CFS, we conclude that CFS impairs the nonconscious high-level face recognition (see Table 3 for a summary of the experimental configuration and the assessment of awareness in the bCFS studies of face recognition). 
Table 3 Experimental configuration and the awareness task in the bCFS studies of face recognition.

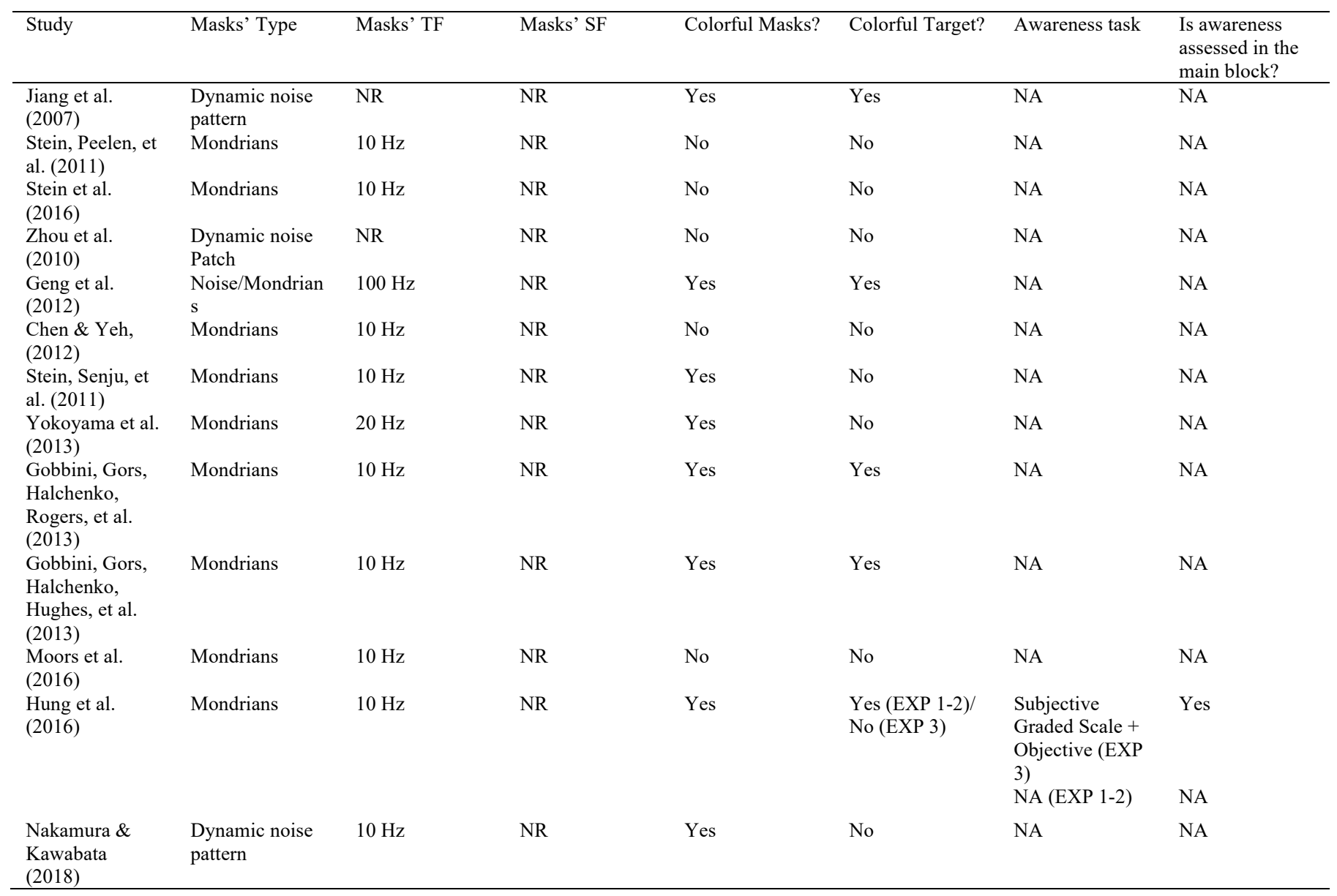

\section{Nonconscious facial expression recognition}

Another important visual category that may show signs of high-level nonconscious perception under the influence of CFS is facial expression. Several studies investigated the possibility of nonconscious facial expression recognition when we render the face stimuli invisible with CFS (Adams, Gray, Garner, \& Graf, 2010; Almeida, Pajtas, Mahon, Nakayama, \& Caramazza, 2013; Faivre, Berthet, \& Kouider, 2012; Tsuchiya, Moradi, Felsen, Yamazaki, \& Adolphs, 2009; Yang, Hong, \& Blake, 2010). Evidence regarding nonconscious facial expression recognition with CFS, however, is not conclusive. Whereas adaptation aftereffect studies provided conflicting evidence for nonconscious facial expression recognition, priming studies showed that an invisible emotional 
face prime can influence how we perceive and evaluate a subsequent target. Moreover, even though bCFS studies showed that fearful faces break the suppression faster, we cannot rule out the possibility of influence of low-level effects on the privilege of fearful faces in bCFS.

Adams et al. (2010) showed that invisible face stimuli with happy, fearful and angry emotions can induce significant high-level facial expression aftereffect (FEA), even though the magnitude of FEA was significantly lower than the visible condition. Yang et al. (2010), on the other hand, found no evidence of nonconscious FEA with CFS (also see Adams, Gray, Garner, \& Graf, 2011). According to the priming studies, an invisible emotional face (prime) can influence how we perceive and evaluate the target stimulus belong to different visual categories, such as unfamiliar alphabets (Almeida et al., 2013; Chiesa, Liuzza, Acciarino, \& Aglioti, 2015; but see Faivre et al., 2012, Experiment 5a and 5b), neutral faces (Anderson et al., 2012; Kring, Siegel, \& Barrett, 2014; Lapate, Rokers, Li, \& Davidson, 2014; but see Faivre et al., 2012, Experiment 5b) and faces with a congruent emotion to the prime (Ye, He, Hu, Yu, \& Wang, 2014). An invisible emotional face also has the ability to influence numerosity estimation (Doi \& Shinohara, 2016) and induce reliable skin conductance response (only when the face is fearful; Lapate et al., 2014; see Table 4 for a summary of the experimental configuration and the assessment of awareness in the priming and adaptation aftereffect studies that evaluated nonconscious facial expression recognition with CFS). 
Table 4 Experimental configuration and the awareness task in the priming and aftereffect studies of nonconscious facial expression recognition.

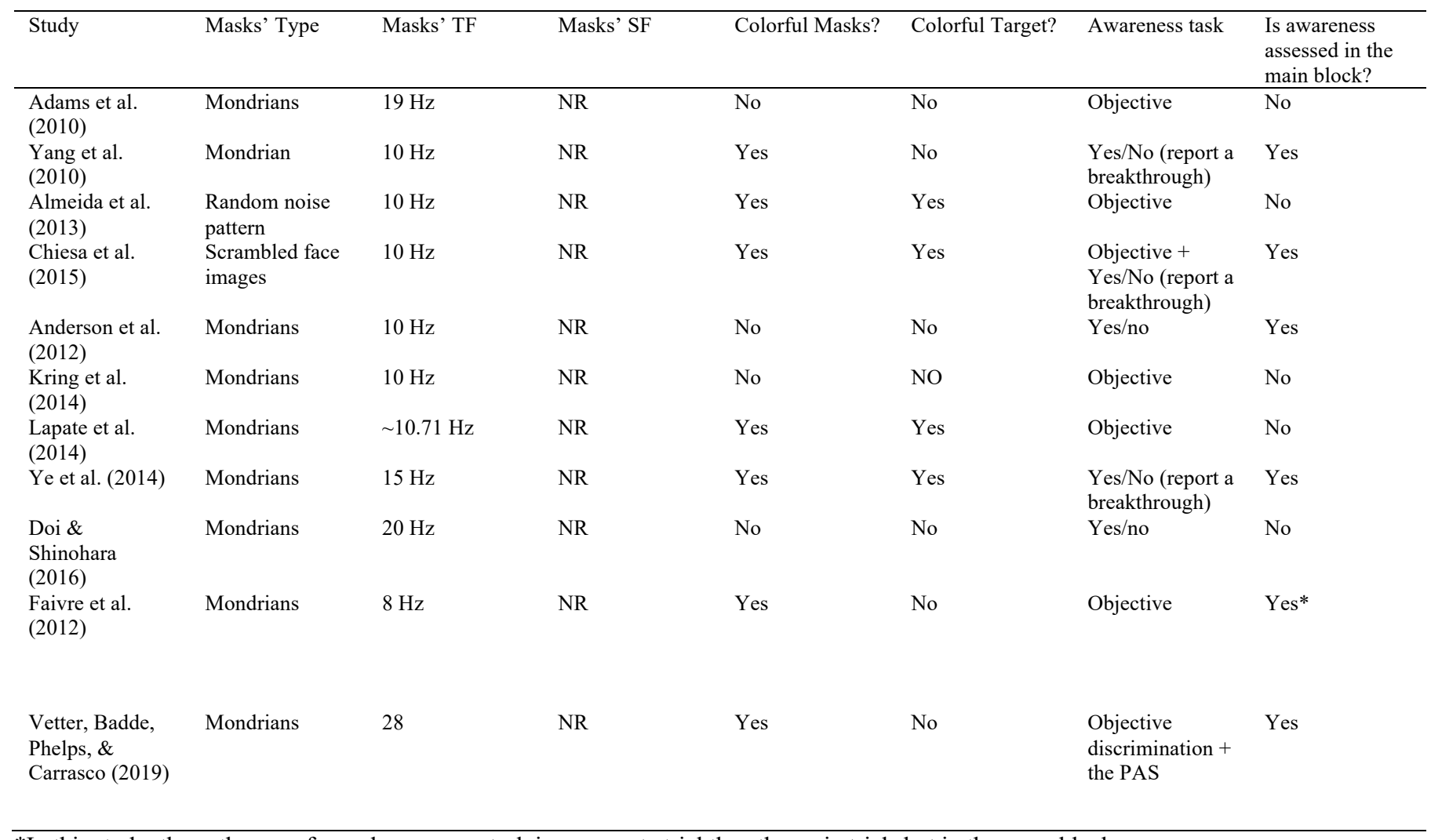

*In this study, the authors performed awareness task in a separate trial than the main trials but in the same block.

Moreover, results from bCFS studies indicate that faces with fearful expression overcome the suppression faster than neutral faces or faces with other emotional expressions (Sterzer et al., 2011; Tsuchiya et al., 2009; Yang et al., 2007), meaning that emotional content of face stimuli is being processed under the influence of CFS. According to Stein, Seymour, Hebart, and Sterzer (2014), the advantage of fearful faces to break the suppression relies on high spatial frequency of fearful faces, meaning that the parvocellular visual pathway is processing the nonconscious information. Although fearful faces overcome the suppression faster than faces with other emotional expressions, it seems this privilege, to some extent, may not be exclusively due to the emotional content of faces but also because of low-level features (Gray, Adams, Hedger, Newton, 
\& Garner, 2013; Hedger, Adams, \& Garner, 2015b). In contrast, Stein and Sterzer (2012) showed that schematic positive (happy) faces break the suppression faster than schematic negative (threatening) faces, but it seems the configuration of faces in their study was responsible for the breaking time difference between positive and negative faces (see Table 5 for a summary of the experimental configuration and the assessment of awareness in the bCFS studies of facial expression recognition).

Emotional faces can also influence eye movements under the influence of CFS. Recently, Vetter et al. (2019) used CFS to suppress emotional faces (fearful, angry and neutral) from awareness while recording participant' eye movement in response to the face stimuli belong to the above-mentioned emotional categories. The results of this study indicated that, compared to the invisible neutral faces, participants direct their gaze toward the invisible fearful faces and away from the invisible angry faces. According to this results, under the influence of CFS, suppressed emotional faces can impact eye movements (Vetter et al., 2019).

Table 5 Experimental configuration and the awareness task in the bCFS studies of facial expression recognition.

\begin{tabular}{|c|c|c|c|c|c|c|c|}
\hline Study & Masks' Type & Masks' TF & Masks' SF & Colorful Masks? & Colorful Target? & Awareness task & $\begin{array}{l}\text { Is awareness } \\
\text { assessed in the } \\
\text { main block? }\end{array}$ \\
\hline $\begin{array}{l}\text { Sterzer et al. } \\
(2011)\end{array}$ & Mondrians & $10 \mathrm{~Hz}$ & NR & No & No & NA & NA \\
\hline $\begin{array}{l}\text { Yang et al. } \\
(2007)\end{array}$ & Mondrians & $10 \mathrm{~Hz}$ & NR & No & No & NA & NA \\
\hline $\begin{array}{l}\text { Gray et al. } \\
(2013)\end{array}$ & Mondrians & $10 \mathrm{~Hz}$ & NR & No & No & NA & NA \\
\hline $\begin{array}{l}\text { Hedger et al. } \\
(2015 b)\end{array}$ & Mondrians & $20 \mathrm{~Hz}$ & NR & No & No & NA & NA \\
\hline $\begin{array}{l}\text { Stein \& Sterzer } \\
(2012)\end{array}$ & Mondrians & $10 \mathrm{~Hz}$ & NR & No & No & NA & NA \\
\hline
\end{tabular}

\footnotetext{
*This study used High-low and unfiltered band pass face stimuli.
} 
Evidence for nonconscious high-level recognition of facial expression under the influence of CFS is not conclusive. Although adaptation, priming, and bCFS studies showed that the perception of facial expression survives under the influence of CFS, low-level features of face stimuli might be responsible for observed nonconscious perception of facial expression. That is, the observed nonconscious recognition of facial expression might be because of the processes of lower-level features but not the emotional content of the emotional faces. Therefore, it is crucial to evaluate the extent to which low-level features and emotional content of face stimuli separately influence nonconscious recognition of facial expression. Based on this, we cannot conclude that high-level facial expression recognition survives under the influence of CFS.

\section{Nonconscious perception of manipulable objects}

Manipulable objects is another important visual category that has been studied extensively with CFS. Evaluating nonconscious recognition of manipulable objects is important because this evaluation provides a mean to evaluate prediction of the two-stream theory of visual perception by Milner and Goodale (2008). According to the two-stream theory of visual perception, visual consciousness is related to neural activities in the ventral pathway (which includes important visual areas such as V4, the occipital face area, and different parts of temporal lobe such as inferotemporal cortex (IT) and superior temporal sulcus (STS)), and activities in the dorsal pathway (which includes areas such as V5, V7, and different parts of parietal lobe, such as intraparietal sulcus) may not be necessary for conscious vision but may support nonconscious vision. In accordance with this theory, Lin and He (2009) proposed that CFS disrupts activities in the ventral pathway but not the dorsal pathway. Therefore, presence of high-level perception of manipulable objects, which are being processed in the dorsal stream, and absence of high-level perception of non-manipulable objects under the influence of CFS is a strong evidence for the two-stream theory of visual 
perception and the aforementioned proposal by Lin and He (2009). Some perceptual priming studies have tried to evaluate this proposal by comparing priming effect of manipulable (tools) versus non-manipulable objects.

Some studies using CFS showed that suppressed tool primes have facilitatory effect on the perception of visible target from the same category (category priming), whereas suppressed nonmanipulable objects did not influence subsequent perception of visible target from the same category (Almeida et al., 2010, 2008). Subsequent studies, however, related this priming effect to the elongation of tools and showed elongated objects other than tools (like a fish or vegetables ${ }^{9}$ ), have similar category priming effect (Almeida et al., 2014; Sakuraba, Sakai, Yamanaka, Yokosawa, \& Hirayama, 2012; for review, see Hebart \& Hesselmann, 2012; Ludwig \& Hesselmann, 2015). Thus, these studies suggest that tool priming is a low-level effect about length and orientation rather than a high-level effect about tool categorization.

Recently, however, both results have been challenged by a series of studies that showed neither tools nor other elongated objects induce category priming (Hesselmann, Darcy, Ludwig, \& Sterzer, 2016; Hesselmann, Darcy, Rothkirch, \& Sterzer, 2018; Rothkirch \& Hesselmann, 2018). There are at least two differences between earlier and more recent studies, which may explain the results. First, the tool targets were all elongated in the earlier studies (Almeida et al., 2010, 2008, 2014; Sakuraba et al., 2012), whereas, more recent studies (Hesselmann et al., 2016, 2018; Rothkirch \& Hesselmann, 2018) used both elongated and non-elongated tool targets. Second, earlier studies (Almeida et al., 2010, 2008, 2014; Sakuraba et al., 2012), used red/green anaglyph glasses, whereas the most recent studies used a mirror stereoscope to induce the rivalry

\footnotetext{
${ }^{9}$ Note that both manipulable and non-manipulable objects can be elongated or non-elongated. An example of an elongated manipulable object is a screwdriver because its length is longer than its width. An example of a non-elongated manipulable object is a door knob because the length is not significantly longer than the width.
} 
(Hesselmann et al., 2016, 2018; but see Rothkirch \& Hesselmann, 2018). The suppression may not be complete with anaglyph glasses and some parts of the "to be suppressed" image might bleed through the glass. Therefore, it is possible that some cross talk exists between the two eyes when we use these glasses (Carmel et al., 2010; but see Hesselmann et al., 2018, Experiment 7). Finally, earlier studies used random noise patterns to induce suppression (Almeida et al., 2010, 2008, 2014; Sakuraba et al., 2012), as compared to the recent studies that used Mondrians to induce suppression (but see Rothkirch \& Hesselmann, 2018). This means that studies that used random noise patterns might have induced an incomplete suppression and a small part of the target might have been visible in these studies. This suggests that some of the effects in the earlier studies are because of incomplete suppression of the target. Therefore, conscious perception of the tool targets has influenced the results of the earlier studies.

Therefore, it seems that CFS interferes with category priming of manipulable objects, even though elongation shape of tools may induce nonconscious shape priming under the influence of CFS (Hesselmann et al., 2016, 2018; Rothkirch \& Hesselmann, 2018). Based on this, CFS studies of manipulable objects did not provide support for the two-stream theory of visual perception and indicated that categorical representation of this class of visual objects does not survive under the influence of CFS. That is, the results of these studies indicate that nonconscious perception of manipulable object does not occur with CFS (see Table 6 for a summary of the experimental configuration and the assessment of awareness in the studies that evaluated nonconscious perception of manipulable objects with CFS). 
Table 6 Experimental configuration and the awareness task in the CFS studies of Manipulable Objects

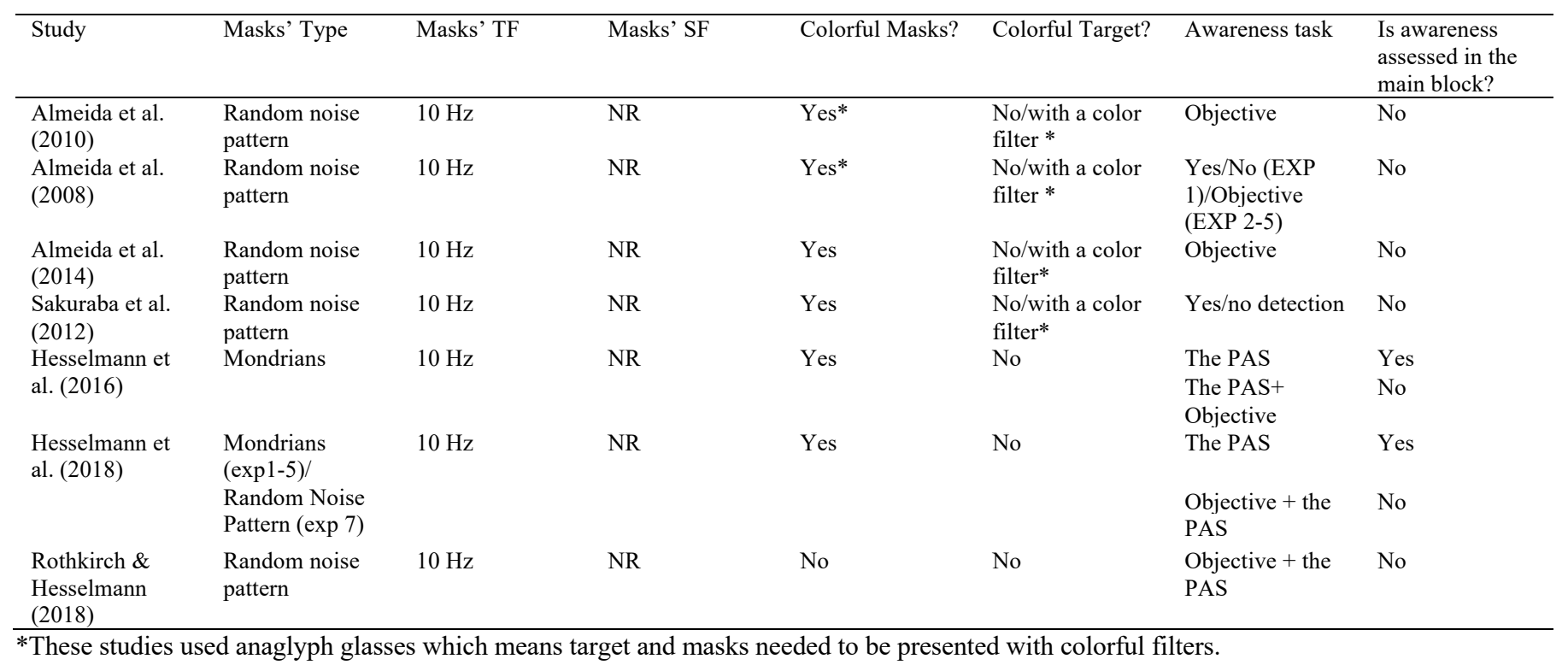

\section{Nonconscious recognition of other visual categories}

Finally, there are handful of other visual categories for which research has examined if there is nonconscious perception under the influence of CFS. Some other studies provided evidence for nonconscious visual abilities such as body posture recognition (Zhan \& de Gelder, 2018), word recognition (Costello et al., 2009; Jiang et al., 2007; Yang \& Yeh, 2011; Zabelina et al., 2013), numeric estimation (Bahrami et al., 2010; but see Hesselmann, Darcy, Sterzer, \& Knops, 2015), recognition of threatening species (Gomes, Silva, Silva, \& Soares, 2017; but see Hedger, Adams, \& Garner, 2015a), discrimination of animals from non-animal stimuli (Koivisto \& Rientamo, 2016), and perceptual grouping (Kimchi, Devyatko, \& Sabary, 2018; Lin \& Yeh, 2016). Furthermore, research showed that fear learning can happen under the influence of CFS (Raio, Carmel, Carrasco, \& Phelps, 2012) and also a previously learned target could break the suppression faster than an unlearned target (Gayet, Paffen, Belopolsky, Theeuwes, \& Van der Stigchel, 2016; 
see Table 7 for a summary of the experimental configuration and the assessment of awareness in the studies that evaluated nonconscious perception of visual categories discussed in this section).

\section{Is there any conclusive evidence for high-level nonconscious perception with CFS?}

The behavioral studies that we reviewed in this section failed to provide conclusive evidence for high-level nonconscious perception under the influence of CFS (see Tables 8 and 9), even though the results of behavioral studies indicate that nonconscious perception of low and mid-level visual information (such as orientation and shape) may survive under the influence of CFS. Although some studies provided evidence for high-level nonconscious perception with CFS, such as bCFS and priming studies of facial expression recognition, they failed to rule out the impact of low-level visual attributes in the observed nonconscious effects. Therefore, the general body of the behavioral literature of CFS did not provide support for high-level nonconscious perception with CFS.

Moreover, the heterogeneity in the experimental configuration and the incongruent assessment of awareness across different studies seem to play a major role in the inconsistent results regarding nonconscious high-level recognition of different categories with CFS. Therefore, it is crucial for the future studies to take these issues into consideration. Indeed, such future studies could draw a better picture regarding level of visual processing in the absence of awareness under the influence of CFS. 
Table 7 Experimental configuration and the awareness task in the CFS studies of a variety of visual categories.

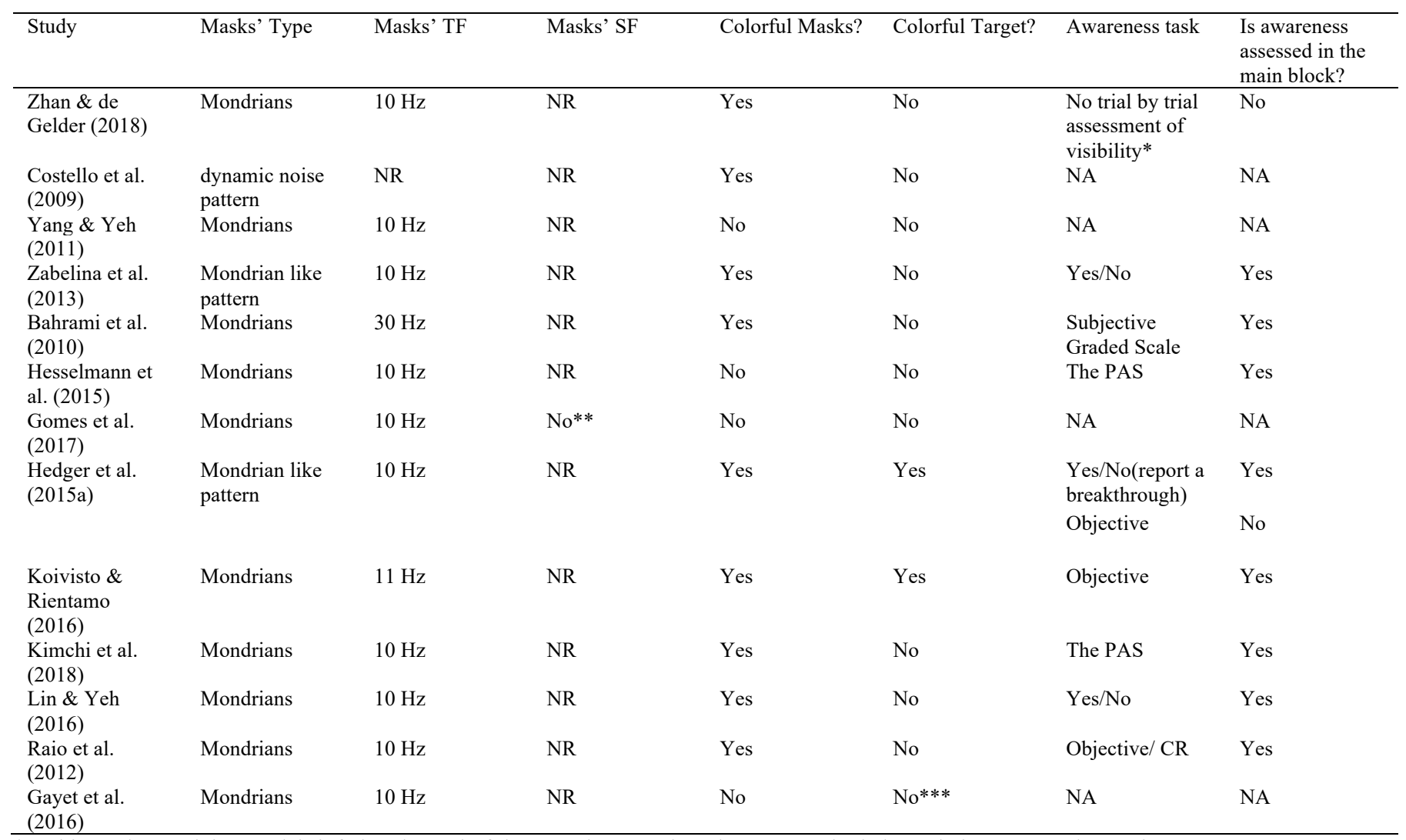

*In this study, participants debriefed at the end of the experiment, when they were asked about their perceptual experiences during the main experiment. **This study reported the spatial frequency band of the target stimuli. ***In this study, the targets were presented inside a colorful annulus.

Table 8 Summary of the evidence for the nonconscious perception of different categories

\begin{tabular}{lllll}
\hline Visual Category & Adaptation & Priming & bCFS & mAFC \\
& Aftereffect & & & \\
& $\checkmark$ & $\checkmark$ & $\checkmark$ & - \\
Frientation & $\times$ & $\times$ & $\checkmark$ & - \\
Face & $\checkmark$ & $?$ & - \\
Manial Expression & $?$ & $\times$ & - & \\
Objects & - & & & - \\
Elongated Objects & - & $?$ & - &
\end{tabular}

This table summarizes the evidence for the nonconscious perception of the main visual categories that we discussed in section "Nonconscious perception with CFS". " $\checkmark$ " indicates the evidence for the existence of the nonconscious perception. " $\times$ " indicates the evidence against the existence of the nonconscious perception. "?" indicates mixed evidence for the existence of the nonconscious perception. "-“ indicates lack of evidence for or against of the nonconscious perception. 
Table 9 Summary of the evidence for nonconscious perception of different visual categories

\begin{tabular}{lc}
\hline Visual category & Evidence for Nonconscious perception \\
\hline Body Posture & $\checkmark$ \\
Word & $\checkmark$ \\
Animals vs. Non-Animal & $\checkmark$ \\
Perceptual Grouping & $\checkmark$ \\
Fear Learning & $?$ \\
Numeric Estimation & $?$ \\
Threatening Species & $?$ \\
\hline
\end{tabular}

\section{The neural correlates of conscious and nonconscious perception with CFS}

One current aim of science of consciousness is to find the neural activities that are associated with conscious experiences (the NCCs; Chalmers, 2000; Crick \& Koch, 2003), especially those neural activities that are substrates of conscious perception (the neural substrates of consciousness; Aru, Bachmann, Singer, \& Melloni, 2012; de Graaf, Hsieh, \& Sack, 2012; for recent reviews on this topic, see Boly et al., 2017; Koch, Massimini, Boly, \& Tononi, 2016; Odegaard, Knight, \& Lau, 2017; Tsuchiya, Wilke, Frässle, \& Lamme, 2015). Critical to understanding of these neurocomputational mechanisms is the differences between conscious and nonconscious perception in term of neural mechanisms. That is, it is critical to isolate the neuro-computational mechanisms that are directly related to conscious perception, from those that are related to the visual processing in the absence of awareness. Many studies have taken advantage of CFS properties in order to evaluate neural basis of conscious and nonconscious perception.

To evaluate the neural basis of nonconscious perception, we must use three criteria that are similar to those we used in the previous section, which we review again here. First, any study investigating the neural basis of a nonconscious high-level recognition of a visual category (such as face or facial expression recognition) must rule out any involvement of low-level features (e.g. 
contours, contrast, shapes) on the observed nonconscious effect and the neural basis of this effect. If not, we cannot conclude that the observed neural activity is representing the high-level representation of the target. Second, the association between a neural activity and nonconscious perception of a specific visual category should be replicated at least once. In the absence of replication, we should be careful in interpreting the observed association between that neural activity and the nonconscious perception. Finally, positive results from bCFS studies is not enough to establish the neural basis of nonconscious perception (Moors et al., 2019).

By taking into account these three criteria, we review some of the CFS studies that evaluated the neural basis of nonconscious perception. First, we start with the primary visual cortex and then continue by discussing evidence regarding the role of the dorsal vs. ventral streams in nonconscious recognition of tools and body expression. Then, we return to discuss the neural basis of nonconscious perception of specific important visual categories with CFS. We discuss the neural correlates of nonconscious face and facial expression recognition. Similar to the previous section, for each visual category, we present a table summarizing the experimental configuration and the assessment of awareness, used in each study.

\section{The Primary Visual Cortex (V1)}

V1 has been a controversial region regarding its association with conscious perception. Some people without V1 show a clear dissociation between conscious and nonconscious perception. That is, people with this condition report that they cannot consciously see target stimuli when they are presented inside the blind field (scotoma), but they can classify different attributes of the target above chance-level in a nonconscious task (blindsight; Weiskrantz, 1986, 1996). Inhibiting V1 activity with transcranial magnetic stimulation (TMS) results in a similar pattern of perception to blindsight (TMS-induced blindsight; Allen, Sumner, \& Chambers, 2014; Boyer, Harrison, \& Ro, 
2005; Ro, Shelton, Lee, \& Chang, 2004). Lack of conscious perception in both blindsight and TMS-induced blindsight implies that V1 is essential for conscious perception (but see Lloyd et al., 2013; Mazzi, Mancini, \& Savazzi, 2014). However, evidence from neuroimaging and single neuron studies of binocular rivalry, have been mixed with respect to the role of V1 in conscious perception. Neuroimaging studies in human participants showed that activities in V1 closely correlate with conscious vision (e.g. Polonsky, Blake, Braun, \& Heeger, 2000), whereas single neuron studies in nonhuman primates did not find supporting evidence for this association (e.g. Leopold \& Logothetis, 1996; for review, see Tong, 2003).

CFS has been employed to evaluate the role of V1 in conscious perception. In a CFS study, Watanabe et al. (2011) manipulated attention and awareness independently and studied the impact of these two factors on blood oxygenation level-dependent (BOLD) signals from V1. Important to this study was the independent manipulation of the attention from visibility. For this, Watanabe et al. (2011) asked participants to report the visibility of the target in the "attention to target block" or to report the detection of a non-target letter at the center of the fixation in the "attention to nontarget block". By using this design, Watanabe et al. (2011) showed that attention but not awareness is associated with change in BOLD signals from V1. This study, however, was criticized for being statistically underpowered (Yuval-Greenberg \& Heeger, 2013; also see Sterzer et al., 2014). Yuval-Greenberg and Heeger (2013) with a similar design but more trials per participant tested the association between conscious perception and V1 BOLD signal and showed that there is a correlation between visibility of target under CFS and the magnitude of BOLD signal from V1.

V1 also processes invisible targets and may be involved in nonconscious perception. For example, Yamashiro et al. (2014) showed robust V1 retinotopic response to the onset of a target 
stimulus, even when the target was invisible. According to this study, the magnitude of V1 responses were not associated with individual differences in suppression duration. The magnitude of retinotopic responses in $\mathrm{V} 3$ and $\mathrm{V} 4 \mathrm{v}$, on the other hand, were associated with suppression duration, meaning weaker response in V3 and V4v, but not in V1 and V2, were associated with longer suppression duration. Regardless of interindividual differences, Yamashiro et al.'s (2014) results indicate that V1 is important for nonconscious perception during CFS. Finally, Bahrami, Lavie, and Rees (2007) showed that V1 is responsive to an invisible target but the intensity of V1 response was reduced when participants had to do a high-load attentional task. Therefore, whereas V1's role in conscious perception is not conclusive, it seems V1 is responsible for nonconscious processing of visual information (see Table 10 for a summary of the experimental configuration and the assessment of awareness in the CFS studies of V1).

Table 10 Experimental configuration and the awareness task in the CFS studies of V1.

\begin{tabular}{|c|c|c|c|c|c|c|c|c|c|}
\hline Study & Masks' Type & Masks' TF & Masks' SF & $\begin{array}{l}\text { Colorful } \\
\text { Masks? }\end{array}$ & $\begin{array}{l}\text { Colorful } \\
\text { Target? }\end{array}$ & $\begin{array}{l}\text { Awareness } \\
\text { task }\end{array}$ & $\begin{array}{l}\text { Is awareness } \\
\text { assessed in } \\
\text { the main } \\
\text { block? }\end{array}$ & $\begin{array}{l}\text { Conscious } \\
\text { Perception }\end{array}$ & $\begin{array}{l}\text { Nonconscio } \\
\text { us } \\
\text { Perception }\end{array}$ \\
\hline $\begin{array}{l}\text { Watanabe et } \\
\text { al. }(2011)\end{array}$ & Mondrians** & $10 \mathrm{~Hz}$ & NR & No & No & $\begin{array}{l}\text { Yes/No } \\
\text { detection }\end{array}$ & Yes & $x$ & - \\
\hline $\begin{array}{l}\text { Yuval- } \\
\text { Greenberg } \\
\text { \& Heeger } \\
(2013)\end{array}$ & Mondrians** & $12 \mathrm{~Hz}$ & $\mathrm{NR}^{*}$ & No & No & $\begin{array}{l}\text { Yes/No } \\
\text { detection }\end{array}$ & No*** & $\checkmark$ & - \\
\hline $\begin{array}{l}\text { Yamashiro } \\
\text { et al. (2014) }\end{array}$ & Mondrians & $7 \mathrm{~Hz}$ & NR & Yes & No & $\begin{array}{l}\text { Yes/No } \\
\text { detection }\end{array}$ & Yes & - & $\checkmark$ \\
\hline $\begin{array}{l}\text { Bahrami et } \\
\text { al. (2007) }\end{array}$ & $\begin{array}{l}\text { Mondrian } \\
\text { like pattern }\end{array}$ & $10 \mathrm{~Hz}$ & NR & No & No & Objective & Yes & - & $\checkmark$ \\
\hline
\end{tabular}

*In this study, the SFs of the different component of the mask were reported. **In these studies, masks (Mondrians) were composed of moving grating patches. ${ }^{* * *}$ In this study, the subjective responses were collected in a pretest run.

\section{Processing of objects in dorsal vs. ventral visual stream}

Researchers have investigated the possibility that the CFS-suppressed target may be represented in higher visual areas. If these areas are involved, this would provide further evidence for the neural basis of nonconscious perception with CFS and resolve some of the inconsistent evidence from behavioral studies as well. In a seminal study in this area, Fang and He (2005) measured BOLD 
signals in response to visible and invisible tools and faces in the regions of interest (ROIs) in the dorsal (V3A, V7 and intraparietal sulcus (IPS)) and ventral (lateral occipital cortex (LO) and the anterior fusiform gyrus) pathways. In response to the invisible tools, dorsal ROIs showed robust BOLD activity. The same response was absent when the invisible target was a face. Ventral ROIs, however, were only responsive to visible tool and face objects, and were unresponsive to the invisible targets belonging to both categories.

The results of Fang and He (2005) supports the two-stream theory of visual perception (Milner \& Goodale, 2008) in which activities in dorsal visual areas are associated with nonconscious perception and activities in ventral visual areas are associated with conscious perception. Therefore, Lin and He (2009) proposed that CFS selectively impairs neural activities in the ventral stream but not the dorsal stream. According to this proposition, dorsal areas might be responsible for nonconscious perception of different object categories under the influence of CFS.

In accordance to the two-stream theory of visual perception (Milner \& Goodale, 2008), the majority of the following studies also pointed to the association between conscious perception and activities in the ventral ROIs. According to these studies, a visible target induces stronger signal in the ventral ROIs than an invisible target (Hesselmann, Hebart, \& Malach, 2011; Hesselmann \& Malach, 2011; Ludwig, Kathmann, Sterzer, \& Hesselmann, 2015; Zhan, Goebel, \& de Gelder, 2018). The results regarding the neural correlates of nonconscious perception with CFS, however, are mixed, and did not provide supporting evidence for this theory. Behavioral priming studies, for example, did not provide evidence for this account and they suggested that areas in the dorsal regions do not remain active in the absence of conscious perception. 
Further evidence from other neuroimaging studies, did not support this account as well and failed to replicate Fang and He's (2005) results. For example, Hesselmann and Malach (2011) showed that, in response to the invisible target, BOLD signals from ventral (LO and posterior fusiform gyrus) and dorsal (V3A, V7 and IPS) ROIs attenuated completely. Hesselmann and Malach (2011), by using a more fine grain analysis method called multivariate pattern analysis (MVPA; Kamitani \& Tong, 2005), decoded responses to the invisible target only in area LO. Moreover, Hesselmann et al. (2011), by matching performance between visible and invisible trials, found similar BOLD results to Hesselmann and Malach's (2011) study. The MVPA analysis by Hesselmann et al. (2011), however, found decodable activity to the invisible tool and face only in the posterior fusiform gyrus. Presence of neural responses in the ventral but not dorsal ROIs in the absence of awareness in these studies clearly contradicts the predictions of the two-stream theory of visual perception.

The results of more recent studies also did not support Fang and He's (2005) results. Ludwig et al. (2015), for example, showed similar stream-invariant BOLD signal reduction in response to invisible tools and faces and showed non-different classification of tools and faces with MVPA, even though by using MVPA, they could decode elongated from non-elongated tools in the fusiform face area (FFA) and right V3A and V7 but not left V3A and V7. Ludwig et al.'s (2015) results imply that shape but not category of the invisible objects might be processed in the dorsal ROIs under the influence of CFS. Moreover, by using MVPA, Fogelson, Kohler, Miller, Granger, and Tse (2014), showed category specific classification in the middle occipital gyrus, the middle occipital and lunate sulci, and the lingual gyrus (all belong to the ventral stream in the occipital cortex). These results again contradict the predictions of the two-stream theory of visual perception. On the other hand, Ludwig, Sterzer, Kathmann, and Hesselmann (2016), using MVPA, 
showed higher than chance category classification in the ventral and dorsal ROIs, when target was presented without the masks or with low contrast masks (visible condition). The classification accuracy, however, fell to the chance-level when the target was masked by high contrast masks (invisible condition) in both ventral and dorsal ROIs. Finally, Tettamanti, Conca, Falini, and Perani (2017) compared responses to manipulable and non-manipulable objects using BOLD and MVPA and found BOLD response to an invisible manipulable object in the dorsal (the ventral premotor area, and inferior and superior parietal cortex), and the ventral (the lateral middle temporal gyrus) ROIs. Non-manipulable objects, on the other hand, caused activity in the bilateral fusiform gyrus. Using MVPA, Tettamanti et al. (2017) decoded manipulable and non-manipulable objects from the ventral premotor cortex, inferior parietal cortex, lateral middle temporal gyrus, and right fusiform gyrus. These results, therefore, did not provide support for the two-stream theory of visual perception.

In summary, studies following up to Fang and He's (2005) study failed to provide evidence for the proposition that neural activities in the dorsal visual stream survive under the influence of CFS (see Table 11). According to these studies invisible tool objects do not induce distinguishable neural activity in the dorsal areas from those in the ventral areas. Based on these studies, the invisible objects belong to this visual category may induce neural activity in both ventral and dorsal areas. Moreover, it seems that the induced neural activities in the dorsal and ventral areas are the results of representation of lower level visual attributes such as elongation and not the results of representation of high-level category information about the manipulable objects. Therefore, the neuroimaging and behavioral studies of manipulable objects did not provide support for high-level processing of this visual category under the influence of CFS. Hence, CFS studies do not support the predictions of the two-stream theory of visual perception. 
Table 11 Summary of the studies that evaluated the involvement of dorsal ROIs in nonconscious recognition of manipulable objects.

\begin{tabular}{|c|c|c|c|c|}
\hline Study & Ventral/BOLD & Ventral/MVPA & Dorsal/BOLD & Dorsal/MVPA \\
\hline Fang \& He's (2005) & $x$ & - & $\checkmark$ & - \\
\hline $\begin{array}{l}\text { Hesselmann \& Malach } \\
\text { (2011) }\end{array}$ & $x$ & $\checkmark$ & $x$ & $x$ \\
\hline $\begin{array}{l}\text { Hesselmann et al. } \\
\text { (2011) }\end{array}$ & $x$ & $\checkmark$ & $x$ & $x$ \\
\hline Ludwig et al. (2015) & $x$ & $x$ & $x$ & $x$ \\
\hline Fogelson et al. (2014) & - & $\checkmark$ & - & $x$ \\
\hline Ludwig et al. (2016) & - & $x$ & - & $x$ \\
\hline $\begin{array}{l}\text { Tettamanti et al. } \\
\text { (2017) }\end{array}$ & $\checkmark$ & $\checkmark$ & $\checkmark$ & $\checkmark$ \\
\hline
\end{tabular}

In contrast with the studies that used tool categories to investigate the association between neural activities in the dorsal visual pathway and nonconscious perception, Zhan et al. (2018) used images of upright and inverted body postures with fearful expression to investigate the dissociation between dorsal and ventral pathways and their role in conscious and nonconscious perception. Because the upright and inverted body postures are not different in shape and elongation, any difference between neural responses to these two categories should be higher level and not reducible to the lower level features (also see Zhan \& de Gelder, 2018). Based on this, Zhan et al. (2018) found that dorsal ROIs (posterior and middle IPS) show higher BOLD activation to the upright than the inverted body postures, and this activity was independent of awareness. They also found higher BOLD activation in ventral ROIs (fusiform body area) in response to the upright body postures, even when the body postures were invisible. Thus, the general pattern of results 
from Zhan et al.'s (2018) study indicated that the BOLD signals in dorsal stream was independent of awareness. Because this study has not been replicated, we warn readers to be cautious on making a firm conclusion regarding its results. In summary, it seems the dorsal visual stream does not process invisible image of tools, though it might be responsible for nonconscious processes of body posture (see Table 12 for a summary of the experimental configuration and the assessment of awareness in the CFS studies of dorsal vs. ventral visual pathway).

Table 12 Experimental configuration and the awareness task in the CFS studies of dorsal vs. ventral visual pathway

\begin{tabular}{|c|c|c|c|c|c|c|c|}
\hline Study & Masks' Type & Masks' TF & Masks' SF & Colorful Masks? & Colorful Target? & Awareness task & $\begin{array}{l}\text { Is awareness } \\
\text { assessed in the } \\
\text { main block? }\end{array}$ \\
\hline $\begin{array}{l}\text { Fang \& He's } \\
(2005)\end{array}$ & Dynamic Noise & $10 \mathrm{~Hz}$ & NR & Yes* & Yes* & Objective & No \\
\hline $\begin{array}{l}\text { Hesselmann et } \\
\text { al. (2011) }\end{array}$ & Mondrians & $10 \mathrm{~Hz}$ & NR & No & No & $\begin{array}{l}\text { Subjective } \\
\text { Graded Scale }\end{array}$ & Yes \\
\hline $\begin{array}{l}\text { Fogelson et al. } \\
\text { (2014) }\end{array}$ & Mondrians & $10 \mathrm{~Hz}$ & NR & Yes & Yes & $\begin{array}{l}\text { Yes/No + } \\
\text { Objective }\end{array}$ & Yes \\
\hline $\begin{array}{l}\text { Ludwig et al. } \\
(2016)\end{array}$ & Mondrians & $10 \mathrm{~Hz}$ & NR & No & No & $\begin{array}{l}\text { Objective + The } \\
\text { PAS }\end{array}$ & Yes \\
\hline $\begin{array}{l}\text { Tettamanti et al. } \\
\text { (2017) }\end{array}$ & Mondrians & $10 \mathrm{~Hz}$ & NR & Yes* & Yes & The PAS & Yes \\
\hline $\begin{array}{l}\text { Zhan et al. } \\
(2018)\end{array}$ & Mondrians & $10 \mathrm{~Hz}$ & NR & Yes & No & $\begin{array}{l}\text { No trial by trial } \\
\text { assessment of } \\
\text { visibility** } \\
\text { Yes/No }\end{array}$ & No \\
\hline
\end{tabular}

*These studies used anaglyph glasses which means target and masks needed to be presented with colorful filters. **In this study, participants debriefed at the end of each experimental run, when they were asked about their perceptual experiences during the run.

\section{Neural correlates of conscious and nonconscious face and facial expression recognition}

Because of the significance of face and facial expression recognition in humans' cognitive life, face recognition and facial expression recognition are two of the best-studied visual categories with CFS, and several studies investigated nonconscious face and facial expression recognition with CFS. Other studies tried to investigate the neural basis of conscious and nonconscious perception of these two categories while suppressing the face stimuli with CFS. 
Jiang and $\mathrm{He}(2006)$ were the first to evaluate the neural differences between conscious and nonconscious perception of face and facial expression (fearful vs. neutral) recognition with CFS. According to Jiang and He (2006), face processing areas (FFA and STS) and amygdala responded significantly to visible face stimuli, with stronger response to the fearful faces than the neutral faces in FFA and amygdala but not in STS. In the invisible condition, FFA responded significantly to both neutral and fearful faces with no difference between two emotions. STS, on the other hand only responded to the invisible fearful but not neutral faces. Finally, the amygdala responded significantly to both fearful and neutral face stimuli, with stronger response to the fearful face than the neutral faces. Based on Jiang and He's results, we suspect that FFA response is associated with nonconscious face recognition (because of similar response to neutral and fearful faces), and amygdala and STS activities are associated with nonconscious facial expression recognition (for similar results with a different sample, see Vizueta, Patrick, Jiang, Thomas, \& He, 2012).

Moreover, Sterzer, Haynes, and Rees (2008) used univariate (BOLD) and multivariate (MVPA) analysis to explore the neural basis of nonconscious processing of face and houses. Whereas univariate analysis did not provide evidence for nonconscious processing of faces and houses in the FFA and parahippocampal place area (PPA) respectively, by using MVPA, Sterzer et al. (2008) decoded visible and invisible faces and houses from FFA and PPA above chancelevel, with higher accuracy in decoding in the visible condition. Based on the results from Jiang and He (2006) and Sterzer et al. (2008), we conclude that FFA might be responsible for nonconscious face recognition, and STS and amygdala might be responsible for nonconscious facial expression recognition. Two EEG/MEG studies from the same labs also support this conclusion. In the first study, Jiang et al. (2009) observed reliable face related negative deflection 
around $170 \mathrm{~ms}$ after the target's onset (N170 component) in the bilateral temporal recording sites, in response to the invisible fearful, but not neutral and scrambled faces. According to Jiang et al. (2009), STS is a generator of this component, even though defining exact origin of an EEG signal may not be possible (see Luck, 2014). In another study, Sterzer, Jalkanen, and Rees (2009) found a stronger M170 (N170 equivalent in MEG) component in the lateral occipitotemporal sites in response to the invisible face than to the invisible house. Hence, these two EEG/MEG studies provided additional support for Jiang and He's (2006) and Sterzer et al. s' (2008) results. Consequently, we consider these early studies as the evidence for the involvement of the FFA in nonconscious face recognition and the involvement of the STS and amygdala in nonconscious facial expression recognition.

Other neuroimaging studies from other labs also supported Jiang and He's (2006) and Sterzer et al.'s (2008) results. For example, Troiani, Price, and Schultz (2014) found greater taskirrelevant activation in the left amygdala and left FFA in response to fearful faces than houses when they masked the targets with checkboards instead of Mondrians or noise maskers. Lapate et al. (2016) showed that not only the right amygdala's response to the fearful faces is independent of visual awareness, but also its response to the invisible fearful faces correlates with likability of the visible neutral faces, presented after the invisible fearful faces. This means activity of the right amygdala might be responsible for nonconscious priming of emotional faces. Another EEG study also supported the earlier results from neuroimaging and EEG/MEG results. In this study, Suzuki and Noguchi (2013) found a larger N170 in response to an invisible upright face than to an invisible inverted face in the occipital, temporal and parietal electrodes. Interestingly, this effect was inverse of the effect in the aware condition (larger N170 in response to inverted than upright faces) and was the result of preserved N170 response to the invisible upright face. In accordance with earlier 
studies, the results from Suzuki and Noguchi's (2013) study indicate that face processing areas are responsive to invisible face stimuli under the influence of CFS.

In contrast to these results, some other studies did not find evidence for the association between the nonconscious face recognition and FFA activity, on one hand, and the nonconscious facial expression recognition and STS and amygdala activity, on the other hand. For example, Tsuchiya et al. (2009, Experiment 3), showed that subject SM, who suffers from complete bilateral amygdala lesion, could detect fearful faces faster than happy faces, similar to the same fear advantage in the control participants. According to these results, the amygdala may not be necessary for nonconscious facial expression (fearful) recognition. Moreover, by using Mondrians as the maskers, Troiani and Schultz (2013) failed to replicate their previous results (Troiani et al., 2014). Based on Troiani and Schultz (2013), fearful face vs. house stimuli do not trigger distinguishable responses in amygdala, FFA and PPA, even though amygdala can discern stimulus present from stimulus absent trials. Therefore, the results of these studies, in contrast to earlier studies, did not provide support for the proposition that face processing areas are responsive to invisible face stimuli under the influence of CFS.

There are also some EEG/MEG results that refute the involvement of face processing areas in nonconscious recognition of face and facial expression under the influence of CFS. For example, Schlossmacher, Junghöfer, Straube, and Bruchmann (2017) showed that there is no difference in the magnitude of the N170 (in the posterior sites) and late positive potential (LPP; in the centroparietal sites) in response to fearful, happy and neutral faces. In addition, Sakuraba, Kobayashi, Sakai, and Yokosawa (2013) found no difference between M170 responses in the invisible face, tools and no-stimulus trials. Sakuraba et al. (2013) found that invisible face stimuli suppress alpha band EEG responses in the occipital sites between 0 to 200 and again between 500 to $1000 \mathrm{~ms}$ 
after stimulus presentation. Finally, according to Geng et al. (2012) nonconscious self-face vs. famous-other face has no impact on N170 amplitude. In contrast, Geng et al. (2012) found reduced vertex positive potential (VPP) in the central and frontocentral sites in response to self-face than famous-other face. In summary, the studies that we reviewed in the past two paragraphs did not provide any indication for the involvement of face processing areas in face and facial expression recognition under the influence of CFS (see Tables 13 and 14).

Table 13 Neural basis of nonconscious face recognition with CFS

\begin{tabular}{lcccc}
\hline Study & FFA & STS & Amygdala & - \\
\hline Jiang \& He (2006) & $\checkmark$ & - & - & - \\
Sterzer et al. (2008) & $\checkmark$ & - & - & $\checkmark$ \\
Sterzer et al. (2009) & - & - & - & $\checkmark$ \\
Suzuki \& Noguchi (2013) & - & - & - \\
Sakuraba et al. (2013) & - & - & $\times$ \\
Geng et al. (2012) & - & - & \\
\end{tabular}

Gaze direction is an important factor in face recognition. As we mentioned in the subsection "Nonconscious face recognition", direct gaze breaks the suppression faster than averted gaze (Chen \& Yeh, 2012; Stein, Senju, et al., 2011; Yokoyama et al., 2013). At least two studies evaluated neural basis of gaze direction (direct vs. averted gaze) with CFS. In an fMRI study, Madipakkam, Rothkirch, Guggenmos, Heinz, and Sterzer (2015) found significantly stronger response to the visible faces with direct gaze in the FFA and IPS and close to significant stronger response to the visible faces with direct gaze in area STS, but not in the amygdala. In the invisible condition, Madipakkam et al. (2015) found significant stronger amygdala and STS and close to 
significant stronger FFA response to the face with averted gaze. These results are in accordance with Jiang and He's (2006) and Sterzer et al.'s (2009) results. In contrast, in an event-related potential (ERP) study, Yokoyama et al. (2013) found significant larger negative VEP deflection (around $200 \mathrm{~ms}$ after stimulus presentation) to the faces with direct gaze in the frontal and parietal sites but not in the occipitotemporal areas. Yokoyama et al.'s (2013) results indicate that temporal areas (STS and FFA) are not responsible for nonconscious recognition of gaze. To summarize, the evidence regarding the neural basis of gaze direction recognition under the influence of CFS is not conclusive. Whereas the neuroimaging results from Madipakkam et al. (2015) provided support for the involvement of face processing areas (the FFA, STS and amygdala), ERP results from Yokoyama et al.'s (2013) study did not support these results, even though a direct comparison between ERP and neuroimaging results may not be possible.

In conclusion, according to the majority of the studies, FFA might be responsible for nonconscious face recognition and amygdala, and STS might be responsible for nonconscious facial expression recognition, although there are studies that do not support these associations. One reason behind this disparity might be related to the maskers' attributes used in the studies. For example, Troiani and colleagues $(2013,2014)$ found different results when they used different maskers. That is, when they used Checkerboards as the maskers, they found neural responses in the left amygdala and left FFA to fearful faces, but when they used Mondrians to achieve the suppression, the neural responses to fearful faces disappeared. Use of different types of masks and incomplete suppression of face stimuli with Checkerboards in Troiani et al. s' (2014) study is the reason for the discordance between these two studies. Moreover, studies we reviewed in this section, presented their maskers with different TFs. This may also explain some of the inconsistent 
results. Therefore, it is possible that some of the studies that found evidence for the aforementioned associations, failed to suppress the face stimuli completely.

Furthermore, studies that found evidence for the involvement of face processing areas in nonconscious recognition of face and facial expression under the influence of CFS do not rule out the response of the ROIs to lower level features of face stimuli. For example, it is not clear if amygdala responses to an invisible fearful face (Jiang \& He, 2006; Lapate et al., 2016; Troiani et al., 2014) is because of the emotional content or the lower level attributes of the faces. By taking the evidence from behavioral studies that we reviewed in the sections "Nonconscious face recognition" and "Nonconscious facial expression recognition" to account, we can assume that the lower level features of the face stimuli have substantive influence on the neural responses in the FFA, the STS and the amygdala. We believe that future studies must investigate the extent of the influence of high-level and lower level attributes of an invisible face stimulus on the neural responses in the aforementioned ROIs. That is, the future studies should investigate if the neural responses in the three main regions are caused by high-level visual information of the faces or by the lower level features (see Table 15 for a summary of the experimental configuration and the assessment of awareness in the studies that evaluated nonconscious perception of visual categories discussed in this section). 
Table 14 Neural basis of nonconscious facial expression recognition with CFS

\begin{tabular}{lcccc}
\hline Study & FFA & STS & Amygdala & N170/M170 \\
\hline Jiang \& He (2006) & - & $\checkmark$ & $\checkmark$ & - \\
Troiani et al. (2014) & $\checkmark$ & - & $\checkmark$ & - \\
Lapate et al. (2016) & - & - & \\
Jiang et al. (2009) & - & & \\
Tsuchiya et al. (2009 & - & - & $\times$ & - \\
Troiani \& Schultz (2013) & & & & \\
Schlossmacher et al. (2017) & - & - & & \\
\end{tabular}

Some authors also directly investigated the neural bases of conscious face perception using CFS. In a recent study, Baroni et al. (2017), utilized CFS to investigate the neural basis of conscious face recognition. In this study, Baroni et al. (2017), collected electrocorticographic (ECoG) responses from five participants with epilepsy, while manipulating the visibility of the face targets by presenting the face stimuli with different contrast. Baroni et al. (2017) used classifiers to decode perceptual state (conscious perception vs. no perception) and contrast of the target stimulus (high to low contrast). According to Baroni et al. (2017), perceptual state of participants was decodable from electrode sites in the face processing areas in the fusiform gyrus, the lateral-temporal /inferior-parietal cortex (based on authors' claim this area might correspond to the STS). This study provided additional support for the view that activities in the higher order face areas (the FFA and the STS) are responsible for conscious face recognition (e.g. Tong, Nakayama, Vaughan, \& Kanwisher, 1998). 
Table 15 Experimental configuration and the awareness task in the CFS studies that evaluated the neural basis of conscious and nonconscious face and facial expression recognition.

\begin{tabular}{|c|c|c|c|c|c|c|c|}
\hline Study & Masks' Type & Masks' TF & Masks' SF & Colorful Masks? & Colorful Target? & Awareness task & $\begin{array}{l}\text { Is awareness } \\
\text { assessed in the } \\
\text { main block? }\end{array}$ \\
\hline $\begin{array}{l}\text { Jiang \& He } \\
(2006)\end{array}$ & Mondrians & $10 \mathrm{~Hz}$ & NR & No* & No & $\begin{array}{l}\text { No trial by trial } \\
\text { assessment of } \\
\text { visibility** } \\
\text { Objective }\end{array}$ & No \\
\hline $\begin{array}{l}\text { Sterzer et al. } \\
(2008)\end{array}$ & $\begin{array}{l}\text { Mondrian like } \\
\text { pattern }\end{array}$ & $30 \mathrm{~Hz}$ & NR & Yes & No & $\mathrm{CR}$ & Yes \\
\hline $\begin{array}{l}\text { Jiang et al. } \\
(2009)\end{array}$ & Mondrians & $20 \mathrm{~Hz}$ & NR & No & No & Objective & No \\
\hline $\begin{array}{l}\text { Sterzer et al. } \\
(2009)\end{array}$ & Mondrians & $30 \mathrm{~Hz}$ & NR & Yes & No & Objective & Yes \\
\hline $\begin{array}{l}\text { Troiani et al. } \\
\text { (2014) }\end{array}$ & Checkerboard & NR & NR & Yes* & Yes & $\begin{array}{l}\text { Yes/No (report a } \\
\text { breakthrough) }\end{array}$ & Yes \\
\hline $\begin{array}{l}\text { Troiani \& } \\
\text { Schultz (2013) }\end{array}$ & Mondrians & $10 \mathrm{~Hz}$ & NR & Yes & No & Yes/No & Yes \\
\hline $\begin{array}{l}\text { Suzuki \& } \\
\text { Noguchi (2013) }\end{array}$ & Mondrians & $20 \mathrm{~Hz}$ & NR & Yes & No & $\begin{array}{l}\text { Yes/ No } \\
\text { Objective }\end{array}$ & $\begin{array}{l}\text { Main } \\
\text { Control }\end{array}$ \\
\hline $\begin{array}{l}\text { Tsuchiya et al. } \\
\text { (2009) }\end{array}$ & Mondrians & $10 \mathrm{~Hz}$ & NR & Yes & No & NA & NA \\
\hline $\begin{array}{l}\text { Schlossmacher } \\
\text { et al. (2017) }\end{array}$ & Mondrians & $20 \mathrm{~Hz}$ & NR & Yes & No & $\begin{array}{l}\text { Yes/No (report a } \\
\text { breakthrough) }\end{array}$ & Main \\
\hline $\begin{array}{l}\text { Sakuraba et al. } \\
\text { (2013 }\end{array}$ & $\begin{array}{l}\text { Dynamic } \\
\text { Random Noise }\end{array}$ & $10 \mathrm{~Hz}$ & NR & Yes* & Yes* & $\begin{array}{l}\text { No Awareness } \\
\text { Measure }\end{array}$ & NA \\
\hline $\begin{array}{l}\text { Madipakkam et } \\
\text { al. (2015) }\end{array}$ & Mondrians & $10 \mathrm{~Hz}$ & NR & No & No & $\mathrm{CR}$ & Main \\
\hline $\begin{array}{l}\text { Yokoyama et al. } \\
\text { (2013) }\end{array}$ & Mondrians & $20 \mathrm{~Hz}$ & NR & Yes & No & Yes/No & Main \\
\hline
\end{tabular}

*These studies used anaglyph glasses which means target and masks needed to be presented with colorful filters. **In this study, participants were asked about their perceptual experiences during the run, after each scanning run.

\section{What is the level visual processing in the absence of awareness under the influence of CFS?}

The neuroimaging (e.g. fMRI) and electrophysiology (e.g. ERP) studies of CFS tried to shed more light on the question that titles this section. To review, there is compelling evidence that V1 is processing visual information in the absence of awareness, even though attention may influence V1 activity in the absence of awareness. Beyond V1, recent CFS studies did not found evidence supporting the Lin and He (2009) proposition that CFS selectively impairs neural activities in the ventral stream but not dorsal. That is, evidence from CFS studies challenges a prediction of the 
two stream theory of conscious perception (Milner \& Goodale, 2008). In addition, the results of some CFS studies indicate that the FFA is responsible for nonconscious face recognition, and the STS and amygdala are responsible for nonconscious recognition of facial expression, even though there are evidence against both of these conclusions. Moreover, neuroimaging and electrophysiology studies that provided support of involvement of the FFA in nonconscious face recognition and the STS and amygdala in nonconscious facial expression recognition failed to exclude the influence of lower level features of the face stimuli on the observed neural responses. Therefore, these studies did not provide conclusive evidence for high-level visual processing under the influence of CFS.

Moreover, the brain recording studies of CFS suffer from the heterogeneity in the experimental configuration and the incongruent assessment of awareness. That is, this heterogeneity may be a reason for some of the discrepancies in the previous studies. Therefore, we can conclude that there is not enough evidence to support the survival of high-level nonconscious visual processing under the influence of CFS, even though evidence support survival of low-level nonconscious visual processing with CFS.

\section{Concluding Remarks}

The aim of this review was to evaluate the ability of the current literature on CFS to answer some of the crucial questions in the science of consciousness. For this, we discussed how different experimental parameters such as maskers' temporal and spatial frequencies impact the depth of CFS-related suppression. We also reviewed the optimal assessment methods to evaluate awareness. Finally, we reviewed the CFS literature regarding the dissociation between conscious and nonconscious perception at both behavioral and neural levels. By reviewing these issues, we hope to provide answer to the questions that we will discuss in the following paragraphs. 
Is there residual high-level perception of different visual categories under the influence of CFS? Behavioral and neural studies of higher-level visual categories with CFS failed to provide substantive evidence for nonconscious high-level perception with CFS. In some cases, in which the nonconscious effects were observed (e.g. nonconscious recognition of manipulable objects and facial expression), the observed effect was because of impact of lower-level features of the target stimuli. That is, the studies that found the nonconscious effect for a high-level visual category failed to rule out the influence of lower level features on the observed effect. In addition to this, other criteria for establishing high-level nonconscious perception with CFS (presence of replication and positive results from studies other than bCFS studies) has not been met by the previous literature. Therefore, we conclude that high-level nonconscious perception is abolished under the influence of CFS. Based on this, we assert that the lower level visual information is being processed in lower (e.g. V1) and higher levels (e.g. FFA and STS) of visual hierarchy with CFS, but CFS decimates high-level visual information.

One can question this conclusion and claim that neuroimaging and electrophysiology studies support the high-level processing of the targets in the absence of awareness with CFS, as we saw in different fMRI and EEG studies. There are at least three problem with this claim: First, neuroimaging and electrophysiology studies did not provide conclusive evidence regarding highlevel visual perception under the influence of CFS. Some studies found supporting evidence for the association between activity in certain ROIs and nonconscious perception of a specific visual category, and some other studies did not find supporting evidence for those associations. Moreover, some of the observed associations might be because of the response of the ROIs to lowlevel or mid-level features of target stimuli. For example, in case of manipulable object recognition, the elongation of the object may explain the activity in the area LO. Therefore, we 
conclude that it is premature to conclude that there is high-level processing of unseen stimuli in CFS.

Furthermore, because some of the neuroimaging and electrophysiology studies did not evaluate conscious and nonconscious perception accurately, we cannot be sure that the observed activities under the influence of CFS represents conscious or nonconscious processing. It is possible that some of the observed activities were not strong enough to cause any conscious and nonconscious perception. Therefore, in absence of rigorous evaluation of conscious and nonconscious perception, neuroimaging and electrophysiology studies cannot provided conclusive evidence regarding the level of visual processing under the influence of CFS. Therefore, we consider the lack of conclusive evidence as an evidence for the impairment of nonconscious perception of high-level visual information under the influence of CFS (also see Moors, 2019).

The puzzle of mechanism of suppression with CFS is also a crucial question that should be discussed. As of now, we could not find any studies that examined the mechanism of suppression with CFS, even though we have some indirect evidence regarding this mechanism. Therefore, future studies must evaluate the mechanism of suppression with CFS. We believe that the future studies should accurately set and report the experimental configurations, which could have a tremendous impact on the depth of suppression with CFS.

Finally, we wonder if results from CFS studies support major theories of conscious perception. The only theories that extensively have been examined using CFS is the two-stream theory of consciousness and both behavioral and neural studies of CFS are not consistent with this theory. Other theories have not been tested extensively with CFS, and we do not have direct evidence from CFS studies to support or disprove these theories. The trend of results from CFS literature, however, is in line with predictions of some of the major theories. That is, the disruption 
of high-level information processing and survival of low-level information processing under the influence of CFS, is in line with some of the major theories of consciousness including the global neural workspace theory (GNW; Dehaene \& Naccache, 2001), the recurrent/feedback model of visual awareness (Lamme, 2006), the information integration theory of consciousness (IIT; Tononi, 2012) and higher-order theory of consciousness (HOT; Lau \& Rosenthal, 2011). CFS studies, however, did not provide evidence in favor of a specific theory.

\section{Acknowledgement}

We would like to thank Drs. Fabian Soto, Bethany Reeb-Sutherland, Jorge Riera Diaz and Sang Wook Hong for their comments on the earlier version of this manuscript.

Appendix A. Important terms and their abbreviations.

\begin{tabular}{|c|c|c|c|}
\hline Abbreviation & Term & Abbreviation & Term \\
\hline bCFS & $\begin{array}{l}\text { Breaking Continuous Flash } \\
\text { Suppression }\end{array}$ & BOLD & $\begin{array}{l}\text { Blood Oxygenation Level- } \\
\text { Dependent }\end{array}$ \\
\hline CFS & $\begin{array}{l}\text { Continuous Flash } \\
\text { Suppression }\end{array}$ & FEA & $\begin{array}{l}\text { Facial Expression } \\
\text { Aftereffect }\end{array}$ \\
\hline FFA & Fusiform Face Area & GRT & $\begin{array}{l}\text { General Recognition } \\
\text { Theory }\end{array}$ \\
\hline IPS & Intraparietal Sulcus & IT & Inferotemporal Cortex \\
\hline LGN & $\begin{array}{l}\text { The Lateral Geniculate } \\
\text { Nucleus }\end{array}$ & LO & Lateral Occipital Cortex \\
\hline LPP & Late Positive Potential & $\mathrm{mAFC}$ & $\begin{array}{l}\text { M-Alternative Forced } \\
\text { Choice }\end{array}$ \\
\hline $\mathrm{mIFC}$ & M-Interval Forced Choice & MVPA & $\begin{array}{l}\text { Multivariate Pattern } \\
\text { Analysis }\end{array}$ \\
\hline NCCs & $\begin{array}{l}\text { The Neural Correlates of } \\
\text { Consciousness }\end{array}$ & PAS & Perceptual Awareness Scale \\
\hline PPA & Parahippocampal Place Area & ROIs & Regions of Interest \\
\hline SDT & Signal Detection Theory & $\mathrm{SF}$ & Spatial Frequency \\
\hline STS & Superior Temporal Sulcus & SvA Curve & $\begin{array}{l}\text { Sensitivity vs. Awareness } \\
\text { Curve }\end{array}$ \\
\hline $\mathrm{TF}$ & Temporal Frequency & TMS & $\begin{array}{l}\text { Transcranial Magnetic } \\
\text { Stimulation }\end{array}$ \\
\hline V1 & The Primary Visual Cortex & VPP & Vertex Positive Potential \\
\hline
\end{tabular}




\section{References}

Adams, W. J., Gray, K. L. H., Garner, M., \& Graf, E. W. (2010). High-level face adaptation without awareness. Psychological Science, 21(2), 205-210. https://doi.org/10.1177/0956797609359508

Adams, W. J., Gray, K. L. H., Garner, M., \& Graf, E. W. (2011). On the "special" status of emotional faces... Comment on Yang, Hong, and Blake (2010). Journal of Vision, 11(3), 10. https://doi.org/10.1167/11.3.10

Afraz, A., \& Cavanagh, P. (2009). The gender-specific face aftereffect is based in retinotopic not spatiotopic coordinates across several natural image transformations. Journal of Vision, 9(10), 10.1-1017. https://doi.org/10.1167/9.10.10

Alais, D., \& Melcher, D. (2007). Strength and coherence of binocular rivalry depends on shared stimulus complexity. Vision Research, 47(2), 269-279. https://doi.org/10.1016/j.visres.2006.09.003

Allen, C. P. G., Sumner, P., \& Chambers, C. D. (2014). The timing and neuroanatomy of conscious vision as revealed by TMS-induced blindsight. Journal of Cognitive Neuroscience, 26(7), 1507-1518. https://doi.org/10.1162/jocn_a_00557

Almeida, J., Mahon, B. Z., \& Caramazza, A. (2010). The role of the dorsal visual processing stream in tool identification. Psychological Science, 21(6), 772-778.

https://doi.org/10.1177/0956797610371343

Almeida, J., Mahon, B. Z., Nakayama, K., \& Caramazza, A. (2008). Unconscious processing dissociates along categorical lines. Proceedings of the National Academy of Sciences, 105(39), 15214-15218. https://doi.org/10.1073/pnas.0805867105

Almeida, J., Mahon, B. Z., Zapater-Raberov, V., Dziuba, A., Cabaço, T., Marques, J. F., \& Caramazza, A. (2014). Grasping with the eyes: The role of elongation in visual recognition of manipulable objects. Cognitive, Affective \& Behavioral Neuroscience, 14(1), 319-335. https://doi.org/10.3758/s13415-013-0208-0 
Almeida, J., Pajtas, P. E., Mahon, B. Z., Nakayama, K., \& Caramazza, A. (2013). Affect of the unconscious: Visually suppressed angry faces modulate our decisions. Cognitive, Affective \& Behavioral Neuroscience, 13(1), 94-101. https://doi.org/10.3758/s13415-012-0133-7

Amihai, I., Deouell, L., \& Bentin, S. (2011). Conscious Awareness is Necessary for Processing Race and Gender Information from Faces. Consciousness and Cognition, 20(2), 269-279. https://doi.org/10.1016/j.concog.2010.08.004

Ananyev, E., Penney, T. B., \& Hsieh, P.-J. B. (2017). Separate requirements for detection and perceptual stability of motion in interocular suppression. Scientific Reports, 7(1), 7230. https://doi.org/10.1038/s41598-017-07805-5

Andersen, L. M., Pedersen, M. N., Sandberg, K., \& Overgaard, M. (2016). Occipital MEG Activity in the Early Time Range (<300 ms) Predicts Graded Changes in Perceptual Consciousness. Cerebral Cortex, 26(6), 2677-2688. https://doi.org/10.1093/cercor/bhv108

Anderson, E., Siegel, E., White, D., \& Barrett, L. F. (2012). Out of sight but not out of mind: Unseen affective faces influence evaluations and social impressions. Emotion, 12(6), 1210-1221. https://doi.org/10.1037/a0027514

Aru, J., Bachmann, T., Singer, W., \& Melloni, L. (2012). Distilling the neural correlates of consciousness. Neuroscience and Biobehavioral Reviews, 36(2), 737-746. https://doi.org/10.1016/j.neubiorev.2011.12.003

Ashby, F. G., \& Soto, F. A. (2015). Multidimensional signal detection theory. In Oxford Library of Psychology. The Oxford handbook of computational and mathematical psychology (pp. 13-34). New York, NY, US: Oxford University Press.

Azzopardi, P., \& Cowey, A. (1997). Is blindsight like normal, near-threshold vision? Proceedings of the National Academy of Sciences, 94(25), 14190-14194. 
Azzopardi, P., \& Cowey, A. (1998). Blindsight and visual awareness. Consciousness and Cognition, 7(3), 292-311. https://doi.org/10.1006/ccog.1998.0358

Bachmann, T., \& Francis, G. (2013). Visual masking: Studying perception, attention, and consciousness. San Diego, CA, US: Elsevier Academic Press.

Bahrami, B., Carmel, D., Walsh, V., Rees, G., \& Lavie, N. (2008). Unconscious orientation processing depends on perceptual load. Journal of Vision, 8(3), 12.1-10. https://doi.org/10.1167/8.3.12

Bahrami, B., Lavie, N., \& Rees, G. (2007). Attentional Load Modulates Responses of Human Primary Visual Cortex to Invisible Stimuli. Current Biology, 17(6), 509-513. https://doi.org/10.1016/j.cub.2007.01.070

Bahrami, B., Vetter, P., Spolaore, E., Pagano, S., Butterworth, B., \& Rees, G. (2010). Unconscious numerical priming despite interocular suppression. Psychological Science, 21(2), 224-233. https://doi.org/10.1177/0956797609360664

Balsdon, T., \& Azzopardi, P. (2015). Absolute and relative blindsight. Consciousness and Cognition, 32, 79-91. https://doi.org/10.1016/j.concog.2014.09.010

Bar, M., \& Biederman, I. (1998). Subliminal visual priming. Psychological Science, 9(6), 464-468. https://doi.org/10.1111/1467-9280.00086

Barbot, A., \& Kouider, S. (2012). Longer is not better: Nonconscious overstimulation reverses priming influences under interocular suppression. Attention, Perception \& Psychophysics, 74(1), 174184. https://doi.org/10.3758/s13414-011-0226-3

Baroni, F., van Kempen, J., Kawasaki, H., Kovach, C. K., Oya, H., Howard, M. A., ... Tsuchiya, N. (2017). Intracranial markers of conscious face perception in humans. Neurolmage, 162, 322-343. https://doi.org/10.1016/j.neuroimage.2017.08.074

Boly, M., Massimini, M., Tsuchiya, N., Postle, B. R., Koch, C., \& Tononi, G. (2017). Are the Neural Correlates of Consciousness in the Front or in the Back of the Cerebral Cortex? Clinical and 
Neuroimaging Evidence. The Journal of Neuroscience, 37(40), 9603-9613.

https://doi.org/10.1523/JNEUROSCI.3218-16.2017

Boyer, J. L., Harrison, S., \& Ro, T. (2005). Unconscious processing of orientation and color without primary visual cortex. Proceedings of the National Academy of Sciences, 102(46), 16875-16879. https://doi.org/10.1073/pnas.0505332102

Carmel, D., Arcaro, M., Kastner, S., \& Hasson, U. (2010). How to Create and Use Binocular Rivalry. Journal of Visualized Experiments, (45). https://doi.org/10.3791/2030

Chalmers, D. J. (2000). What is a Neural Correlate of Consciousness? In T. Metzinger (Ed.), Neural Correlates of Consciousness: Empirical and Conceptual Questions. https://doi.org/10.1093/acprof:oso/9780195311105.001.0001

Charles, L., Van Opstal, F., Marti, S., \& Dehaene, S. (2013). Distinct brain mechanisms for conscious versus subliminal error detection. Neurolmage, 73, 80-94. https://doi.org/10.1016/j.neuroimage.2013.01.054

Chen, Y.-C., \& Yeh, S.-L. (2012). Look into my eyes and I will see you: Unconscious processing of human gaze. Consciousness and Cognition, 21(4), 1703-1710. https://doi.org/10.1016/j.concog.2012.10.001

Chiesa, P. A., Liuzza, M. T., Acciarino, A., \& Aglioti, S. M. (2015). Subliminal perception of others' physical pain and pleasure. Experimental Brain Research, 233(8), 2373-2382. https://doi.org/10.1007/s00221-015-4307-8

Costello, P., Jiang, Y., Baartman, B., McGlennen, K., \& He, S. (2009). Semantic and subword priming during binocular suppression. Consciousness and Cognition, 18(2), 375-382. https://doi.org/10.1016/j.concog.2009.02.003

Cowey, A. (2010). The blindsight saga. Experimental Brain Research, 200(1), 3-24. https://doi.org/10.1007/s00221-009-1914-2 
Crick, F., \& Koch, C. (2003). A framework for consciousness. Nature Neuroscience, 6(2), 119-126. https://doi.org/10.1038/nn0203-119

de Graaf, T. A., Hsieh, P.-J., \& Sack, A. T. (2012). The "correlates" in neural correlates of consciousness. Neuroscience and Biobehavioral Reviews, 36(1), 191-197. https://doi.org/10.1016/j.neubiorev.2011.05.012

Dehaene, S., \& Naccache, L. (2001). Towards a cognitive neuroscience of consciousness: Basic evidence and a workspace framework. Cognition, 79(1-2), 1-37.

Doi, H., \& Shinohara, K. (2016). Emotional faces influence numerosity estimation without awareness. Cognitive Processing, 17(4), 389-397. https://doi.org/10.1007/s10339-016-0774-5

Drewes, J., Zhu, W., \& Melcher, D. (2018). The edge of awareness: Mask spatial density, but not color, determines optimal temporal frequency for continuous flash suppression. Journal of Vision, 18(1), 12. https://doi.org/10.1167/18.1.12

Dykstra, A. R., Cariani, P. A., \& Gutschalk, A. (2017). A roadmap for the study of conscious audition and its neural basis. Philosophical Transactions of the Royal Society of London. Series B, Biological Sciences, 372(1714). https://doi.org/10.1098/rstb.2016.0103

Evans, S., \& Azzopardi, P. (2007). Evaluation of a "bias-free" measure of awareness. Spatial Vision, 20(12), 61-77.

Faivre, N., Berthet, V., \& Kouider, S. (2012). Nonconscious influences from emotional faces: A comparison of visual crowding, masking, and continuous flash suppression. Frontiers in Psychology, 3, 129. https://doi.org/10.3389/fpsyg.2012.00129

Faivre, N., Berthet, V., \& Kouider, S. (2014). Sustained invisibility through crowding and continuous flash suppression: A comparative review. Frontiers in Psychology, 5. https://doi.org/10.3389/fpsyg.2014.00475 
Fang, F., \& He, S. (2005). Cortical responses to invisible objects in the human dorsal and ventral pathways. Nature Neuroscience, 8(10), 1380-1385. https://doi.org/10.1038/nn1537

Fleming, S. M., \& Lau, H. C. (2014). How to measure metacognition. Frontiers in Human Neuroscience, 8. https://doi.org/10.3389/fnhum.2014.00443

Fogelson, S. V., Kohler, P. J., Miller, K. J., Granger, R., \& Tse, P. U. (2014). Unconscious neural processing differs with method used to render stimuli invisible. Frontiers in Psychology, 5, 601. https://doi.org/10.3389/fpsyg.2014.00601

Gayet, S., Paffen, C. L. E., Belopolsky, A. V., Theeuwes, J., \& Van der Stigchel, S. (2016). Visual input signaling threat gains preferential access to awareness in a breaking continuous flash suppression paradigm. Cognition, 149, 77-83. https://doi.org/10.1016/j.cognition.2016.01.009

Gayet, S., Van der Stigchel, S., \& Paffen, C. L. E. (2014). Breaking continuous flash suppression: Competing for consciousness on the pre-semantic battlefield. Frontiers in Psychology, 5, 460. https://doi.org/10.3389/fpsyg.2014.00460

Gelbard-Sagiv, H., Faivre, N., Mudrik, L., \& Koch, C. (2016). Low-level awareness accompanies "unconscious" high-level processing during continuous flash suppression. Journal of Vision, 16(1), 3. https://doi.org/10.1167/16.1.3

Geng, H., Zhang, S., Li, Q., Tao, R., \& Xu, S. (2012). Dissociations of subliminal and supraliminal self-face from other-face processing: Behavioral and ERP evidence. Neuropsychologia, 50(12), 29332942. https://doi.org/10.1016/j.neuropsychologia.2012.07.040

Gobbini, M. I., Gors, J. D., Halchenko, Y. O., Hughes, H. C., \& Cipolli, C. (2013). Processing of invisible social cues. Consciousness and Cognition, 22(3), 765-770. https://doi.org/10.1016/j.concog.2013.05.002 
Gobbini, M. I., Gors, J. D., Halchenko, Y. O., Rogers, C., Guntupalli, J. S., Hughes, H., \& Cipolli, C. (2013). Prioritized Detection of Personally Familiar Faces. PLoS ONE, 8(6), e66620. https://doi.org/10.1371/journal.pone.0066620

Goldiamond, I. (1958). Indicators of perception: I. Subliminal perception, subception, unconscious perception: An analysis in terms of psychophysical indicator methodology. Psychological Bulletin, 55(6), 373-411. https://doi.org/10.1037/h0046992

Gomes, N., Silva, S., Silva, C. F., \& Soares, S. C. (2017). Beware the serpent: The advantage of ecologically-relevant stimuli in accessing visual awareness. Evolution and Human Behavior, 38(2), 227-234. https://doi.org/10.1016/j.evolhumbehav.2016.10.004

Gray, K. L. H., Adams, W. J., Hedger, N., Newton, K. E., \& Garner, M. (2013). Faces and awareness: Lowlevel, not emotional factors determine perceptual dominance. Emotion, 13(3), 537-544. https://doi.org/10.1037/a0031403

Green, D. M., \& Swets, J. A. (1966). Signal detection theory and psychophysics. Oxford, England: John Wiley.

Han, S., \& Alais, D. (2018). Strength of continuous flash suppression is optimal when target and masker modulation rates are matched. Journal of Vision, 18(3), 3. https://doi.org/10.1167/18.3.3

Han, S., Blake, R., \& Alais, D. (2018). Slow and steady, not fast and furious: Slow temporal modulation strengthens continuous flash suppression. Consciousness and Cognition, 58, 10-19. https://doi.org/10.1016/j.concog.2017.12.007

Han, S., Lunghi, C., \& Alais, D. (2016). The temporal frequency tuning of continuous flash suppression reveals peak suppression at very low frequencies. Scientific Reports, 6, 35723. https://doi.org/10.1038/srep35723 
Hebart, M. N., \& Hesselmann, G. (2012). What Visual Information Is Processed in the Human Dorsal Stream? Journal of Neuroscience, 32(24), 8107-8109. https://doi.org/10.1523/JNEUROSCI.146212.2012

Hedger, N., Adams, W. J., \& Garner, M. (2015a). Autonomic arousal and attentional orienting to visual threat are predicted by awareness. Journal of Experimental Psychology: Human Perception and Performance, 41(3), 798-806. https://doi.org/10.1037/xhp0000051

Hedger, N., Adams, W. J., \& Garner, M. (2015b). Fearful faces have a sensory advantage in the competition for awareness. Journal of Experimental Psychology: Human Perception and Performance, 41(6), 1748-1757. https://doi.org/10.1037/xhp0000127

Heeks, F., \& Azzopardi, P. (2015). Thresholds for detection and awareness of masked facial stimuli. Consciousness and Cognition, 32, 68-78. https://doi.org/10.1016/j.concog.2014.09.009 Hesselmann, G., Darcy, N., Ludwig, K., \& Sterzer, P. (2016). Priming in a shape task but not in a category task under continuous flash suppression. Journal of Vision, 16(3), 17. https://doi.org/10.1167/16.3.17

Hesselmann, G., Darcy, N., Rothkirch, M., \& Sterzer, P. (2018). Investigating masked priming along the "vision-for-perception" and "vision-for-action" dimensions of unconscious processing. Journal of Experimental Psychology: General. https://doi.org/10.1037/xge0000420

Hesselmann, G., Darcy, N., Sterzer, P., \& Knops, A. (2015). Exploring the boundary conditions of unconscious numerical priming effects with continuous flash suppression. Consciousness and Cognition, 31, 60-72. https://doi.org/10.1016/j.concog.2014.10.009

Hesselmann, G., Hebart, M., \& Malach, R. (2011). Differential BOLD activity associated with subjective and objective reports during "blindsight" in normal observers. The Journal of Neuroscience, 31(36), 12936-12944. https://doi.org/10.1523/JNEUROSCI.1556-11.2011 
Hesselmann, G., \& Malach, R. (2011). The link between fMRI-BOLD activation and perceptual awareness is "stream-invariant" in the human visual system. Cerebral Cortex, 21(12), 2829-2837. https://doi.org/10.1093/cercor/bhr085

Hong, S. W. (2015). Radial bias for orientation and direction of motion modulates access to visual awareness during continuous flash suppression. Journal of Vision, 15(1), 15.1.3. https://doi.org/10.1167/15.1.3

Hong, S. W., \& Blake, R. (2009). Interocular suppression differentially affects achromatic and chromatic mechanisms. Attention, Perception \& Psychophysics, 71(2), 403-411. https://doi.org/10.3758/APP.71.2.403

Hung, S.-M., Nieh, C.-H., \& Hsieh, P.-J. (2016). Unconscious processing of facial attractiveness: Invisible attractive faces orient visual attention. Scientific Reports, 6, 37117. https://doi.org/10.1038/srep37117

Izatt, G., Dubois, J., Faivre, N., \& Koch, C. (2014). A direct comparison of unconscious face processing under masking and interocular suppression. Frontiers in Psychology, 5. https://doi.org/10.3389/fpsyg.2014.00659

Jachs, B., Blanco, M. J., Grantham-Hill, S., \& Soto, D. (2015). On the independence of visual awareness and metacognition: A signal detection theoretic analysis. Journal of Experimental Psychology: Human Perception and Performance, 41(2), 269-276. https://doi.org/10.1037/xhp0000026

Jiang, Y., Costello, P., \& He, S. (2007). Processing of invisible stimuli: Advantage of upright faces and recognizable words in overcoming interocular suppression. Psychological Science, 18(4), 349355. https://doi.org/10.1111/j.1467-9280.2007.01902.x

Jiang, Y., \& He, S. (2006). Cortical responses to invisible faces: Dissociating subsystems for facialinformation processing. Current Biology, 16(20), 2023-2029. https://doi.org/10.1016/j.cub.2006.08.084 
Jiang, Y., Shannon, R. W., Vizueta, N., Bernat, E. M., Patrick, C. J., \& He, S. (2009). Dynamics of processing invisible faces in the brain: Automatic neural encoding of facial expression information. Neurolmage, 44(3), 1171-1177. https://doi.org/10.1016/j.neuroimage.2008.09.038

Kamitani, Y., \& Tong, F. (2005). Decoding the visual and subjective contents of the human brain. Nature Neuroscience, 8(5), 679-685. https://doi.org/10.1038/nn1444

Kanai, R., Tsuchiya, N., \& Verstraten, F. A. J. (2006). The scope and limits of top-down attention in unconscious visual processing. Current Biology, 16(23), 2332-2336. https://doi.org/10.1016/j.cub.2006.10.001

Kaunitz, L. N., Fracasso, A., Skujevskis, M., \& Melcher, D. (2014). Waves of visibility: Probing the depth of inter-ocular suppression with transient and sustained targets. Frontiers in Psychology, 5, 804. https://doi.org/10.3389/fpsyg.2014.00804

Kimchi, R., Devyatko, D., \& Sabary, S. (2018). Can perceptual grouping unfold in the absence of awareness? Comparing grouping during continuous flash suppression and sandwich masking. Consciousness and Cognition, 60, 37-51. https://doi.org/10.1016/j.concog.2018.02.009

Koch, C., Massimini, M., Boly, M., \& Tononi, G. (2016). Neural correlates of consciousness: Progress and problems. Nature Reviews. Neuroscience, 17(5), 307-321. https://doi.org/10.1038/nrn.2016.22

Koivisto, M., \& Grassini, S. (2018). Unconscious response priming during continuous flash suppression. PLoS ONE, 13(2). https://doi.org/10.1371/journal.pone.0192201

Koivisto, M., \& Rientamo, E. (2016). Unconscious vision spots the animal but not the dog: Masked priming of natural scenes. Consciousness and Cognition, 41, 10-23. https://doi.org/10.1016/j.concog.2016.01.008

Koriat, A. (2007). Metacognition and consciousness. In P. D. Zelazo, M. Moscovitch, \& E. Thompson (Eds.), The Cambridge handbook of consciousness (pp. 289-325). https://doi.org/10.1017/СВ09780511816789.012 
Kring, A. M., Siegel, E. H., \& Barrett, L. F. (2014). Unseen Affective Faces Influence Person Perception Judgments in Schizophrenia. Clinical Psychological Science, 2(4), 443-454. https://doi.org/10.1177/2167702614536161

Kunimoto, C., Miller, J., \& Pashler, H. (2001). Confidence and accuracy of near-threshold discrimination responses. Consciousness and Cognition, 10(3), 294-340. https://doi.org/10.1006/ccog.2000.0494

Lamme, V. A. F. (2006). Towards a true neural stance on consciousness. Trends in Cognitive Sciences, 10(11), 494-501. https://doi.org/10.1016/j.tics.2006.09.001

Lapate, R. C., Rokers, B., Li, T., \& Davidson, R. J. (2014). Nonconscious emotional activation colors first impressions: A regulatory role for conscious awareness. Psychological Science, 25(2), 349-357. https://doi.org/10.1177/0956797613503175

Lapate, R. C., Rokers, B., Tromp, D. P. M., Orfali, N. S., Oler, J. A., Doran, S. T., ... Davidson, R. J. (2016). Awareness of Emotional Stimuli Determines the Behavioral Consequences of Amygdala Activation and Amygdala-Prefrontal Connectivity. Scientific Reports, 6, 25826. https://doi.org/10.1038/srep25826

Lau, H. C. (2008). Are we studying consciousness yet? In Frontiers of Consciousness: Chichele Lectures. Oxford, NY: Oxford University Press.

Lau, H., \& Rosenthal, D. (2011). Empirical support for higher-order theories of conscious awareness. Trends in Cognitive Sciences, 15(8), 365-373. https://doi.org/10.1016/j.tics.2011.05.009 Leopold, D. A., \& Logothetis, N. K. (1996). Activity changes in early visual cortex reflect monkeys' percepts during binocular rivalry. Nature, 379(6565), 549-553. https://doi.org/10.1038/379549a0 
Lesmes, L. A., Lu, Z.-L., Baek, J., Tran, N., Dosher, B. A., \& Albright, T. D. (2015). Developing Bayesian adaptive methods for estimating sensitivity thresholds ( $\left.d^{\prime}\right)$ in Yes-No and forced-choice tasks. Frontiers in Psychology, 6. https://doi.org/10.3389/fpsyg.2015.01070

Lin, S.-Y., \& Yeh, S.-L. (2016). Interocular grouping without awareness. Vision Research, 121, 23-30. https://doi.org/10.1016/j.visres.2016.01.004

Lin, Z., \& He, S. (2009). Seeing the invisible: The scope and limits of unconscious processing in binocular rivalry. Progress in Neurobiology, 87(4), 195-211. https://doi.org/10.1016/j.pneurobio.2008.09.002

Lloyd, D. A., Abrahamyan, A., \& Harris, J. A. (2013). Brain-stimulation induced blindsight: Unconscious vision or response bias? PLOS ONE, 8(12), e82828. https://doi.org/10.1371/journal.pone.0082828

Luck, S. J. (2014). An Introduction to The Event-Related Potential Technique / Request PDF (2nd ed.). Cambridge, MA: MIT Press.

Ludwig, K., \& Hesselmann, G. (2015). Weighing the evidence for a dorsal processing bias under continuous flash suppression. Consciousness and Cognition, 35, 251-259. https://doi.org/10.1016/j.concog.2014.12.010

Ludwig, K., Kathmann, N., Sterzer, P., \& Hesselmann, G. (2015). Investigating category- and shapeselective neural processing in ventral and dorsal visual stream under interocular suppression. Human Brain Mapping, 36(1), 137-149. https://doi.org/10.1002/hbm.22618

Ludwig, K., Sterzer, P., Kathmann, N., \& Hesselmann, G. (2016). Differential modulation of visual object processing in dorsal and ventral stream by stimulus visibility. Cortex, 83, 113-123. https://doi.org/10.1016/j.cortex.2016.07.002

Mack, A. (2003). Inattentional blindness: Looking without seeing. Current Directions in Psychological Science, 12(5), 180-184. https://doi.org/10.1111/1467-8721.01256 
Macmillan, N. A., \& Creelman, C. D. (2004). Detection theory: A user's guide. Mahwah, NJ: Erlbaum Inc. Madipakkam, A. R., Rothkirch, M., Guggenmos, M., Heinz, A., \& Sterzer, P. (2015). Gaze Direction Modulates the Relation between Neural Responses to Faces and Visual Awareness. The Journal of Neuroscience, 35(39), 13287-13299. https://doi.org/10.1523/JNEUROSCI.0815-15.2015

Maniscalco, B., \& Lau, H. (2012). A signal detection theoretic approach for estimating metacognitive sensitivity from confidence ratings. Consciousness and Cognition, 21(1), 422-430. https://doi.org/10.1016/j.concog.2011.09.021

Maniscalco, B., \& Lau, H. (2014). Signal Detection Theory Analysis of Type 1 and Type 2 Data: Meta- d', Response-Specific Meta- $d^{\prime}$, and the Unequal Variance SDT Model. In S. M. Fleming \& C. D. Frith (Eds.), The cognitive neuroscience of metacognition. New York, NY, US: Springer-Verlag Publishing.

Martens, S., \& Wyble, B. (2010). The attentional blink: Past, present, and future of a blind spot in perceptual awareness. Neuroscience and Biobehavioral Reviews, 34(6), 947-957. https://doi.org/10.1016/j.neubiorev.2009.12.005

Mazzi, C., Bagattini, C., \& Savazzi, S. (2016). Blind-Sight vs. Degraded-Sight: Different Measures Tell a Different Story. Frontiers in Psychology, 7. https://doi.org/10.3389/fpsyg.2016.00901

Mazzi, C., Mancini, F., \& Savazzi, S. (2014). Can IPS reach visual awareness without V1? Evidence from TMS in healthy subjects and hemianopic patients. Neuropsychologia, 64, 134-144. https://doi.org/10.1016/j.neuropsychologia.2014.09.026

Metcalfe, J., \& Schwartz, B. L. (2016). The Ghost in the Machine. In J. Dunlosky \& S. K. Tauber (Eds.), The Oxford Handbook of Metamemory. Retrieved from http://www.oxfordhandbooks.com/view/10.1093/oxfordhb/9780199336746.001.0001/oxfordh b-9780199336746-e-19 
Milner, A. D., \& Goodale, M. A. (2008). Two visual systems re-viewed. Neuropsychologia, 46(3), 774-785. https://doi.org/10.1016/j.neuropsychologia.2007.10.005

Moors, P. (2019). What's up with high-level processing during continuous flash suppression? In G. Hesselmann (Ed.), Transitions Between Consciousness and Unconsciousness. New York, NY: Routledge.

Moors, P., Gayet, S., Hedger, N., Stein, T., Sterzer, P., van Ee, R., ... Hesselmann, G. (2019). Three Criteria for Evaluating High-Level Processing in Continuous Flash Suppression. Trends in Cognitive Sciences, 23(4), 267-269. https://doi.org/10.1016/j.tics.2019.01.008

Moors, P., Hesselmann, G., Wagemans, J., \& van Ee, R. (2017). Continuous Flash Suppression: Stimulus Fractionation rather than Integration. Trends in Cognitive Sciences, 21(10), 719-721. https://doi.org/10.1016/j.tics.2017.06.005

Moors, P., Wagemans, J., \& de-Wit, L. (2014). Moving stimuli are less effectively masked using traditional continuous flash suppression (CFS) compared to a moving Mondrian mask (MMM): A test case for feature-selective suppression and retinotopic adaptation. PloS One, 9(5), e98298. https://doi.org/10.1371/journal.pone.0098298

Moors, P., Wagemans, J., \& de-Wit, L. (2016). Faces in commonly experienced configurations enter awareness faster due to their curvature relative to fixation. PeerJ, 4, e1565. https://doi.org/10.7717/peerj.1565

Moradi, F., Koch, C., \& Shimojo, S. (2005). Face adaptation depends on seeing the face. Neuron, 45(1), 169-175. https://doi.org/10.1016/j.neuron.2004.12.018

Nakamura, K., \& Kawabata, H. (2018). Preferential access to awareness of attractive faces in a breaking continuous flash suppression paradigm. Consciousness and Cognition, 65, 71-82. https://doi.org/10.1016/j.concog.2018.07.010 
Newell, B. R., \& Shanks, D. R. (2014). Unconscious influences on decision making: A critical review. The Behavioral and Brain Sciences, 37(1), 1-19. https://doi.org/10.1017/S0140525X12003214

Ng, M., Boynton, G. M., \& Fine, I. (2008). Face adaptation does not improve performance on search or discrimination tasks. Journal of Vision, 8(1), 1.1-20. https://doi.org/10.1167/8.1.1

Odegaard, B., Knight, R. T., \& Lau, H. (2017). Should a Few Null Findings Falsify Prefrontal Theories of Conscious Perception? The Journal of Neuroscience, 37(40), 9593-9602. https://doi.org/10.1523/JNEUROSCI.3217-16.2017

Overgaard, M., Fehl, K., Mouridsen, K., Bergholt, B., \& Cleeremans, A. (2008). Seeing without Seeing? Degraded Conscious Vision in a Blindsight Patient. PLOS ONE, 3(8). https://doi.org/10.1371/journal.pone.0003028

Overgaard, M., Rote, J., Mouridsen, K., \& Ramsøy, T. Z. (2006). Is conscious perception gradual or dichotomous? A comparison of report methodologies during a visual task. Consciousness and Cognition, 15(4), 700-708. https://doi.org/10.1016/j.concog.2006.04.002

Peremen, Z., \& Lamy, D. (2014). Comparing unconscious processing during continuous flash suppression and meta-contrast masking just under the limen of consciousness. Frontiers in Psychology, 5. https://doi.org/10.3389/fpsyg.2014.00969

Persuh, M. (2018). Measuring Perceptual Consciousness. Frontiers in Psychology, 8. https://doi.org/10.3389/fpsyg.2017.02320

Peters, M. A. K., \& Lau, H. (2015). Human observers have optimal introspective access to perceptual processes even for visually masked stimuli. ELife, 4, e09651. https://doi.org/10.7554/eLife.09651

Peters, M. A. K., Ro, T., \& Lau, H. (2016). Who's afraid of response bias? Neuroscience of Consciousness, 2016(1). https://doi.org/10.1093/nc/niw001 
Polonsky, A., Blake, R., Braun, J., \& Heeger, D. J. (2000). Neuronal activity in human primary visual cortex correlates with perception during binocular rivalry. Nature Neuroscience, 3(11), 1153. https://doi.org/10.1038/80676

Pournaghdali, A., Schwartz, B. L., Hays, J. S., \& Soto, F. (under revision). Sensitivity vs. Awareness Curve: A Novel Model-Based Analysis to Uncover the Processes Underlying Nonconscious Perception [Preprint]. https://doi.org/10.31234/osf.io/akem2

Raio, C. M., Carmel, D., Carrasco, M., \& Phelps, E. A. (2012). Nonconscious fear is quickly acquired but swiftly forgotten. Current Biology, 22(12), R477-R479. https://doi.org/10.1016/j.cub.2012.04.023

Rams $\varnothing$ y, T. Z., \& Overgaard, M. (2004). Introspection and subliminal perception. Phenomenology and the Cognitive Sciences, 3(1), 1-23. https://doi.org/10.1023/B:PHEN.0000041900.30172.e8

Reder, L. M. (1996). Implicit Memory and Metacognition. New York, NY: Psychology Press.

Ro, T., Shelton, D., Lee, O. L., \& Chang, E. (2004). Extrageniculate mediation of unconscious vision in transcranial magnetic stimulation-induced blindsight. Proceedings of the National Academy of Sciences of the United States of America, 101(26), 9933-9935. https://doi.org/10.1073/pnas.0403061101

Rosenthal, D. (2019). Consciousness and confidence. Neuropsychologia, 128, 255-265. https://doi.org/10.1016/j.neuropsychologia.2018.01.018

Rothkirch, M., \& Hesselmann, G. (2018). No evidence for dorsal-stream-based priming under continuous flash suppression. Consciousness and Cognition, 64, 84-94. https://doi.org/10.1016/j.concog.2018.05.011

Sakuraba, S., Kobayashi, H., Sakai, S., \& Yokosawa, K. (2013). Alpha-band rhythm modulation under the condition of subliminal face presentation: MEG study. Conference Proceedings: 35th Annual 
International Conference of the IEEE Engineering in Medicine and Biology Society., 2013, 69096912. https://doi.org/10.1109/EMBC.2013.6611146

Sakuraba, S., Sakai, S., Yamanaka, M., Yokosawa, K., \& Hirayama, K. (2012). Does the human dorsal stream really process a category for tools? The Journal of Neuroscience, 32(11), 3949-3953. https://doi.org/10.1523/JNEUROSCl.3973-11.2012

Sandberg, K., Bibby, B. M., \& Overgaard, M. (2013). Measuring and testing awareness of emotional face expressions. Consciousness and Cognition, 22(3), 806-809. https://doi.org/10.1016/j.concog.2013.04.015

Sandberg, K., \& Overgaard, M. (2015). Using the perceptual awareness scale (PAS). In M. Overgaard (Ed.), Behavioral Methods in Consciousness Research. New York, NY: Oxford University Press.

Sandberg, K., Timmermans, B., Overgaard, M., \& Cleeremans, A. (2010). Measuring consciousness: Is one measure better than the other? Consciousness and Cognition, 19(4), 1069-1078. https://doi.org/10.1016/j.concog.2009.12.013

Schlossmacher, I., Junghöfer, M., Straube, T., \& Bruchmann, M. (2017). No differential effects to facial expressions under continuous flash suppression: An event-related potentials study. Neurolmage, 163, 276-285. https://doi.org/10.1016/j.neuroimage.2017.09.034

Schmidt, T. (2015). Invisible Stimuli, Implicit Thresholds: Why Invisibility Judgments Cannot be Interpreted in Isolation. Advances in Cognitive Psychology, 11(2), 31-41. https://doi.org/10.5709/acp-0169-3

Sergent, C., \& Dehaene, S. (2004). Is consciousness a gradual phenomenon? Evidence for an all-or-none bifurcation during the attentional blink. Psychological Science, 15(11), 720-728. https://doi.org/10.1111/j.0956-7976.2004.00748.x 
Shanks, D. R. (2017). Regressive research: The pitfalls of post hoc data selection in the study of unconscious mental processes. Psychonomic Bulletin \& Review, 24(3), 752-775. https://doi.org/10.3758/s13423-016-1170-y

Shin, K., Stolte, M., \& Chong, S. C. (2009). The effect of spatial attention on invisible stimuli. Attention, Perception \& Psychophysics, 71(7), 1507-1513. https://doi.org/10.3758/APP.71.7.1507

Song, C., \& Yao, H. (2016). Unconscious processing of invisible visual stimuli. Scientific Reports, 6, 38917. https://doi.org/10.1038/srep38917

Soto, F. A., Zheng, E., Fonseca, J., \& Ashby, F. G. (2017). Testing Separability and Independence of Perceptual Dimensions with General Recognition Theory: A Tutorial and New R Package (grtools). Frontiers in Psychology, 8, 696. https://doi.org/10.3389/fpsyg.2017.00696

Stein, T., Hebart, M. N., \& Sterzer, P. (2011). Breaking continuous flash suppression: A new measure of unconscious processing during interocular suppression? Frontiers in Human Neuroscience, 5, 167. https://doi.org/10.3389/fnhum.2011.00167

Stein, T., Peelen, M. V., \& Sterzer, P. (2011). Adults' awareness of faces follows newborns' looking preferences. PloS One, 6(12), e29361. https://doi.org/10.1371/journal.pone.0029361

Stein, T., Peelen, M. V., \& Sterzer, P. (2012). Eye gaze adaptation under interocular suppression. Journal of Vision, 12(7), 1. https://doi.org/10.1167/12.7.1

Stein, T., Reeder, R. R., \& Peelen, M. V. (2016). Privileged access to awareness for faces and objects of expertise. Journal of Experimental Psychology: Human Perception and Performance, 42(6), 788798. https://doi.org/10.1037/xhp0000188

Stein, T., Senju, A., Peelen, M. V., \& Sterzer, P. (2011). Eye contact facilitates awareness of faces during interocular suppression. Cognition, 119(2), 307-311. https://doi.org/10.1016/j.cognition.2011.01.008 
Stein, T., Seymour, K., Hebart, M. N., \& Sterzer, P. (2014). Rapid fear detection relies on high spatial frequencies. Psychological Science, 25(2), 566-574. https://doi.org/10.1177/0956797613512509

Stein, T., \& Sterzer, P. (2011). High-level face shape adaptation depends on visual awareness: Evidence from continuous flash suppression. Journal of Vision, 11(8), 5. https://doi.org/10.1167/11.8.5

Stein, T., \& Sterzer, P. (2012). Not just another face in the crowd: Detecting emotional schematic faces during continuous flash suppression. Emotion, 12(5), 988-996.

http://dx.doi.org/10.1037/a0026944

Sterzer, P., Haynes, J.-D., \& Rees, G. (2008). Fine-scale activity patterns in high-level visual areas encode the category of invisible objects. Journal of Vision, 8(15), 10.1-12. https://doi.org/10.1167/8.15.10

Sterzer, P., Hilgenfeldt, T., Freudenberg, P., Bermpohl, F., \& Adli, M. (2011). Access of emotional information to visual awareness in patients with major depressive disorder. Psychological Medicine, 41(8), 1615-1624. https://doi.org/10.1017/S0033291710002540

Sterzer, P., Jalkanen, L., \& Rees, G. (2009). Electromagnetic responses to invisible face stimuli during binocular suppression. Neurolmage, 46(3), 803-808. https://doi.org/10.1016/j.neuroimage.2009.02.046

Sterzer, P., Stein, T., Ludwig, K., Rothkirch, M., \& Hesselmann, G. (2014). Neural processing of visual information under interocular suppression: A critical review. Frontiers in Psychology, 5, 453. https://doi.org/10.3389/fpsyg.2014.00453

Suzuki, M., \& Noguchi, Y. (2013). Reversal of the face-inversion effect in N170 under unconscious visual processing. Neuropsychologia, 51(3), 400-409. https://doi.org/10.1016/j.neuropsychologia.2012.11.021 
Tagliabue, C. F., Mazzi, C., Bagattini, C., \& Savazzi, S. (2016). Early Local Activity in Temporal Areas Reflects Graded Content of Visual Perception. Frontiers in Psychology, 7. https://doi.org/10.3389/fpsyg.2016.00572

Tettamanti, M., Conca, F., Falini, A., \& Perani, D. (2017). Unaware Processing of Tools in the Neural System for Object-Directed Action Representation. The Journal of Neuroscience, 37(44), 1071210724. https://doi.org/10.1523/JNEUROSCI.1061-17.2017

Timmermans, B., \& Cleeremans, A. (2015). How can we measure awareness? An overview of current methods. In M. Overgaard (Ed.), Behavioral Methods in Consciousness Research. Retrieved from http://www.oxfordscholarship.com/view/10.1093/acprof:oso/9780199688890.001.0001/acprof -9780199688890 -chapter-3

Tong, F. (2003). Primary visual cortex and visual awareness. Nature Reviews. Neuroscience, 4(3), 219229. https://doi.org/10.1038/nrn1055

Tong, F., Meng, M., \& Blake, R. (2006). Neural bases of binocular rivalry. Trends in Cognitive Sciences, 10(11), 502-511. https://doi.org/10.1016/j.tics.2006.09.003

Tong, F., Nakayama, K., Vaughan, J. T., \& Kanwisher, N. (1998). Binocular rivalry and visual awareness in human extrastriate cortex. Neuron, 21(4), 753-759.

Tononi, G. (2012). Integrated information theory of consciousness: An updated account. Archives Italiennes De Biologie, 150(2-3), 56-90. https://doi.org/10.4449/aib.v149i5.1388

Troiani, V., Price, E. T., \& Schultz, R. T. (2014). Unseen fearful faces promote amygdala guidance of attention. Social Cognitive and Affective Neuroscience, 9(2), 133-140. https://doi.org/10.1093/scan/nss116

Troiani, V., \& Schultz, R. T. (2013). Amygdala, pulvinar, and inferior parietal cortex contribute to early processing of faces without awareness. Frontiers in Human Neuroscience, 7, 241. https://doi.org/10.3389/fnhum.2013.00241 
Tsuchiya, N., \& Koch, C. (2005). Continuous flash suppression reduces negative afterimages. Nature Neuroscience, 8(8), 1096-1101. https://doi.org/10.1038/nn1500

Tsuchiya, N., Koch, C., Gilroy, L. A., \& Blake, R. (2006). Depth of interocular suppression associated with continuous flash suppression, flash suppression, and binocular rivalry. Journal of Vision, 6(10), 1068-1078. https://doi.org/10.1167/6.10.6

Tsuchiya, N., Moradi, F., Felsen, C., Yamazaki, M., \& Adolphs, R. (2009). Intact rapid detection of fearful faces in the absence of the amygdala. Nature Neuroscience, 12(10), 1224-1225. https://doi.org/10.1038/nn.2380

Tsuchiya, N., Wilke, M., Frässle, S., \& Lamme, V. A. F. (2015). No-Report Paradigms: Extracting the True Neural Correlates of Consciousness. Trends in Cognitive Sciences, 19(12), 757-770. https://doi.org/10.1016/j.tics.2015.10.002

Vetter, P., Badde, S., Phelps, E. A., \& Carrasco, M. (2019). Emotional faces guide the eyes in the absence of awareness. ELife, 8. https://doi.org/10.7554/eLife.43467

Vizueta, N., Patrick, C. J., Jiang, Y., Thomas, K. M., \& He, S. (2012). Dispositional fear, negative affectivity, and neuroimaging response to visually suppressed emotional faces. Neurolmage, 59(1), 761771. https://doi.org/10.1016/j.neuroimage.2011.07.015

Watanabe, M., Cheng, K., Murayama, Y., Ueno, K., Asamizuya, T., Tanaka, K., \& Logothetis, N. (2011). Attention but not awareness modulates the BOLD signal in the human V1 during binocular suppression. Science, 334(6057), 829-831. https://doi.org/10.1126/science.1203161

Weiskrantz, L. (1986). Blindsight: A case study and implications. Oxford, NY: Oxford University Press. Weiskrantz, L. (1996). Blindsight revisited. Current Opinion in Neurobiology, 6(2), 215-220.

Weiskrantz, L., Barbur, J. L., \& Sahraie, A. (1995). Parameters affecting conscious versus unconscious visual discrimination with damage to the visual cortex (V1). Proceedings of the National Academy of Sciences of the United States of America, 92(13), 6122-6126. 
Witt, J. K., Taylor, J. E. T., Sugovic, M., \& Wixted, J. T. (2015). Signal Detection Measures Cannot Distinguish Perceptual Biases from Response Biases. Perception, 44(3), 289-300. https://doi.org/10.1068/p7908

Xu, S., Zhang, S., \& Geng, H. (2011). Gaze-induced joint attention persists under high perceptual load and does not depend on awareness. Vision Research, 51(18), 2048-2056. https://doi.org/10.1016/j.visres.2011.07.023

Yamashiro, H., Yamamoto, H., Mano, H., Umeda, M., Higuchi, T., \& Saiki, J. (2014). Activity in early visual areas predicts interindividual differences in binocular rivalry dynamics. Journal of Neurophysiology, 111(6), 1190-1202. https://doi.org/10.1152/jn.00509.2013

Yang, E., \& Blake, R. (2012). Deconstructing continuous flash suppression. Journal of Vision, 12(3), 8. https://doi.org/10.1167/12.3.8

Yang, E., Brascamp, J., Kang, M.-S., \& Blake, R. (2014). On the use of continuous flash suppression for the study of visual processing outside of awareness. Frontiers in Psychology, 5, 724. https://doi.org/10.3389/fpsyg.2014.00724

Yang, E., Hong, S.-W., \& Blake, R. (2010). Adaptation aftereffects to facial expressions suppressed from visual awareness. Journal of Vision, 10(12), 24. https://doi.org/10.1167/10.12.24

Yang, E., Zald, D. H., \& Blake, R. (2007). Fearful expressions gain preferential access to awareness during continuous flash suppression. Emotion, 7(4), 882-886. https://doi.org/10.1037/15283542.7.4.882

Yang, Y.-H., \& Yeh, S.-L. (2011). Accessing the meaning of invisible words. Consciousness and Cognition, 20(2), 223-233. https://doi.org/10.1016/j.concog.2010.07.005

Ye, X., He, S., Hu, Y., Yu, Y. Q., \& Wang, K. (2014). Interference between conscious and unconscious facial expression information. PloS One, 9(8), e105156. https://doi.org/10.1371/journal.pone.0105156 
Yokoyama, T., Noguchi, Y., \& Kita, S. (2013). Unconscious processing of direct gaze: Evidence from an ERP study. Neuropsychologia, 51(7), 1161-1168. https://doi.org/10.1016/j.neuropsychologia.2013.04.002

Yoshida, M., \& Isa, T. (2015). Signal detection analysis of blindsight in monkeys. Scientific Reports, 5, 10755. https://doi.org/10.1038/srep10755

Yuval-Greenberg, S., \& Heeger, D. J. (2013). Continuous flash suppression modulates cortical activity in early visual cortex. The Journal of Neuroscience, 33(23), 9635-9643. https://doi.org/10.1523/JNEUROSCI.4612-12.2013

Zabelina, D. L., Guzman-Martinez, E., Ortega, L., Grabowecky, M., Suzuki, S., \& Beeman, M. (2013). Suppressed semantic information accelerates analytic problem solving. Psychonomic Bulletin \& Review, 20(3), 581-585. https://doi.org/10.3758/s13423-012-0364-1

Zhan, M., \& de Gelder, B. (2018). Unconscious fearful body perception enhances discrimination of conscious anger expressions under continuous flash suppression. Neuropsychologia, 128, 325331. https://doi.org/10.1016/j.neuropsychologia.2018.04.019

Zhan, M., Engelen, T., \& de Gelder, B. (2018). Influence of continuous flash suppression mask frequency on stimulus visibility. Neuropsychologia, 128, 65-72. https://doi.org/10.1016/j.neuropsychologia.2018.05.012

Zhan, M., Goebel, R., \& de Gelder, B. (2018). Ventral and Dorsal Pathways Relate Differently to Visual Awareness of Body Postures under Continuous Flash Suppression. ENeuro, 5(1). https://doi.org/10.1523/ENEURO.0285-17.2017

Zhou, G., Zhang, L., Liu, J., Yang, J., \& Qu, Z. (2010). Specificity of face processing without awareness. Consciousness and Cognition, 19(1), 408-412. https://doi.org/10.1016/j.concog.2009.12.009 
Zhu, W., Drewes, J., \& Melcher, D. (2016). Time for Awareness: The Influence of Temporal Properties of the Mask on Continuous Flash Suppression Effectiveness. PLOS ONE, 11(7).

https://doi.org/10.1371/journal.pone.0159206 